\title{
Nutrients in the Atlantic Thermocline
}

\author{
M. KAWASE AND J. L. SARMiento
}

Geophysical Fluid Dynamics Program, Princeton University, New Jersey

\begin{abstract}
A set of maps are presented of nutrient distribution on isopycnal surfaces in the North and tropical Atlantic Ocean main thermocline. The data used in producing these maps are from the Transient Tracers in the Oceans (TTO) North Atlantic Study and Tropical Atlantic Study, an associated German study (Meteor 56/5), two cross-Atlantic sections from cruise 109 of the Atlantis II, and the GEOSECS program. The nutrient distributions reflect primarily the sources at the northern and southern outcrops of the isopycnal surfaces, the in situ regeneration due to decomposition of sinking organic materials, and the interior physical processes as inferred from thermocline models and the distribution of conservative properties such as salinity. However, silica also exhibits behavior that cannot be explained by in situ regeneration. A simple phenomenological model suggests that cross-isopycnal advection and mixing in the equatorial region may play an important role in the nutrient dynamics. These data should prove of great value in constraining models of physical as well as biogeochemical processes.
\end{abstract}

\section{INTRODUCTION}

The recent completion of the Transient Tracers in the Oceans (TTO) Tropical Atlantic Study, when added to previous TTO and GEOSECS studies, provides an excellent set of nutrient observations for the North and tropical Atlantic. This paper presents an analysis of these and other data from the same period on isopycnal surfaces in the North Atlantic main thermocline. Our intention in this paper is to point out the major features of the TTO/GEOSECS nutrient distributions on isopycnal surfaces in the main thermocline. A major point of interest in these data is evidence suggesting the importance of cross-isopycnal advection and mixing in the equatorial region at depths several hundred meters below the surface. The mechanism for this mixing is not certain at this point.

The value of "isopycnal analysis" arises primarily from the fact that in the absence of mixing and other diabatic processes, potential density is a conserved quantity following the water parcel. Also one can argue from an energetic viewpoint that waters of the same potential density will tend to mix more readily than waters of different potential density, and therefore the principal axes of the mixing coefficient tensor are aligned parallel to and perpendicular to the surface of constant potential density [Montgomery, 1938]. These are perhaps the most powerful simplifying assumptions one can make in unraveling the three-dimensional complexities of property distributions in the ocean. Montgomery was one of the first to analyze property distributions on isopycnal surfaces. Reid and Lynn [1971] and Ivers [1975] developed techniques for extending isopycnal analysis to the deep oceans where the use of a single reference pressure for calculating potential density leads to difficulties. A number of recent studies of the thermocline have employed isopycnal analysis. Thus Broecker and Ostlund [1979] investigated the structure of distributions of potential temperature, salinity, oxygen, silica, "NO" and "PO" (linear combinations of oxygen concentration with nitrate and silica, respectively, which are in theory conservative), and tritium on a single potential density surface $\left(\sigma_{\theta}=26.8\right)$ in the Atlantic using GEOSECS data. Broecker and Takahashi [1981] studied potential temperature, salinity, oxygen, silica, nitrate, barium, alkalinity, and "NO" as well as radioactive tracers ${ }^{14} \mathrm{C}$ and

Copyright 1985 by the American Geophysical Union.

Paper number $5 \mathrm{C} 0431$.

0148-0227/85/005C-0431\$05.00
${ }^{226} \mathrm{Ra}$, on the $\sigma_{1}=32.05$ surface in the Intermediate Water range. McDowell [1982] analyzed temperature, salinity, and oxygen on several potential density levels that lie in the North Atlantic thermocline and below and calculated the contributions from various source waters at each location in the North Atlantic. Sarmiento et al. [1982a] described the distributions of salinity, potential vorticity, and tritium in 1972 on six potential density levels in the North and tropical Atlantic thermocline. The distribution of potential vorticity was also investigated by McDowell et al. [1982]

This study is an extension of the work by Sarmiento et al. [1982a] to nutrients. Here we have produced a set of water mass property maps and property-property plots on the same six potential density surfaces that were investigated in the earlier study. Our aim is to point out major water sources and major physical/biogeochemical processes acting on the Atlantic thermocline water. In this context, property-property plots can complement spatial distribution maps in important ways in that they tend to eliminate features caused by pure advection and to highlight the water masses involved in the circulation. Moreover, they point to the occurrence of crossisopycnal and nonconservative processes, which are not readily appreciated from spatial distribution maps.

We shall look at five water properties: salinity, oxygen, apparent oxygen utilization (AOU), silica, and nitrate. Spatial distribution maps are produced for each quantity for each layer. The maps are produced by the objective mapping technique developed and described by Sarmiento et al. [1982b]. This technique was designed to produce maps of gross distributions of properties on a quasi-horizontal surface, and its characteristic feature is an anisotropic autocorrelation function with a greater zonal extent. For the details of the mapping scheme, the reader is referred to the above paper.

\section{DATA}

The data used for this study were obtained during the GEOSECS Atlantic Study, Meteor cruise 56, leg 5 (R. Schlitzer et al., unpublished manuscript, 1985), the Transient Tracers in the Oceans North and Tropical Atlantic studies (TTO NAS and TAS respectively), and the two cross-Atlantic sections from cruise 109 of the Atlantis II [Roemmich and Wunsch, 1985]. The distribution of stations is shown in Figure 1. The TTO, Meteor, and Atlantis $I I$ cruises combined provide us with a coverage of the North and tropical Atlantic that is almost comparable in density with the International Geo- 


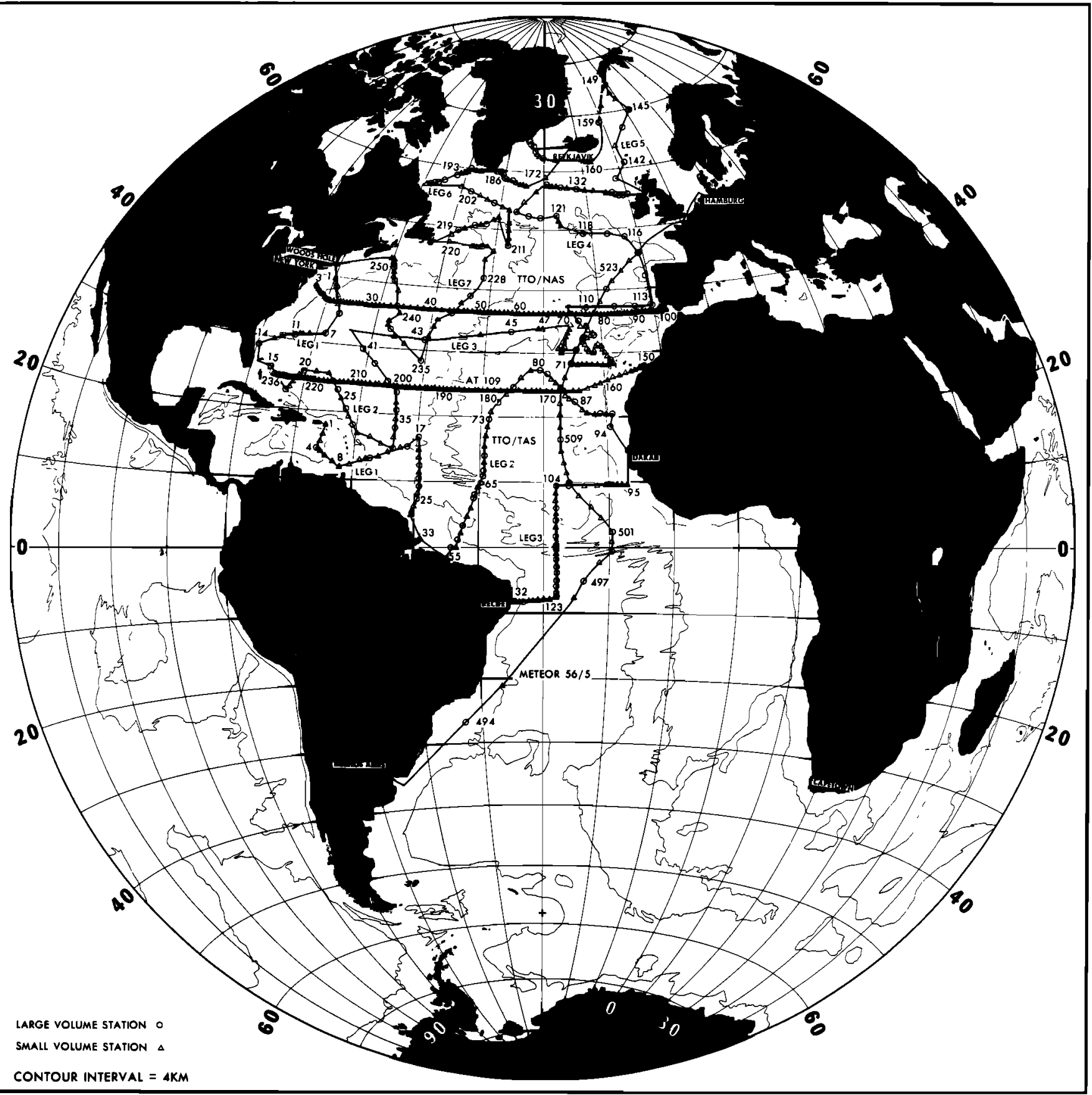

Fig. 1a. TTO, Meteor 56/5, Atlantis II 109 .

Fig. 1. Distribution of stations that were used in this study.

physical Year (IGY) data set. They cover the area north of the line connecting, approximately, Cape Palmas on the Ivory Coast and Recife, Brazil. South of this line, only GEOSECS data were used in producing the maps and plots. Our discussion concentrates inevitably on the North and tropical Atlantic. South Atlantic data were used mostly to determine the characteristics of source waters in that region.

These data span a time period of 10 years. There have been reports that comparison of the most recent data with those of the IGY period revealed systematic changes in the hydrography of the deep North Atlantic [Brewer et al., 1983; Roemmich and Wunsch, 1984]. However, in our data at the depth of the thermocline, scatter of individual data was large enough to obscure systematic changes, if any, between the GEOSECS and the TTO/Meteor/Atlantis II cruises.

All quantities were linearly interpolated from levels of observation to potential density surfaces. Potential density was calculated using the new UNESCO equation of state for seawater [UNESCO, 1981] together with Fofonoffs [1977] algorithm for calculating potential temperature and Bryden's [1973] formula for adiabatic temperature gradient. For each surface the line of wintertime outcrop was determined from the ocean atlas by Levitus [1982] for each hemisphere, and those stations lying poleward of outcrops were excluded. The aim here is to concentrate on water masses that are part of the permanent thermocline. 


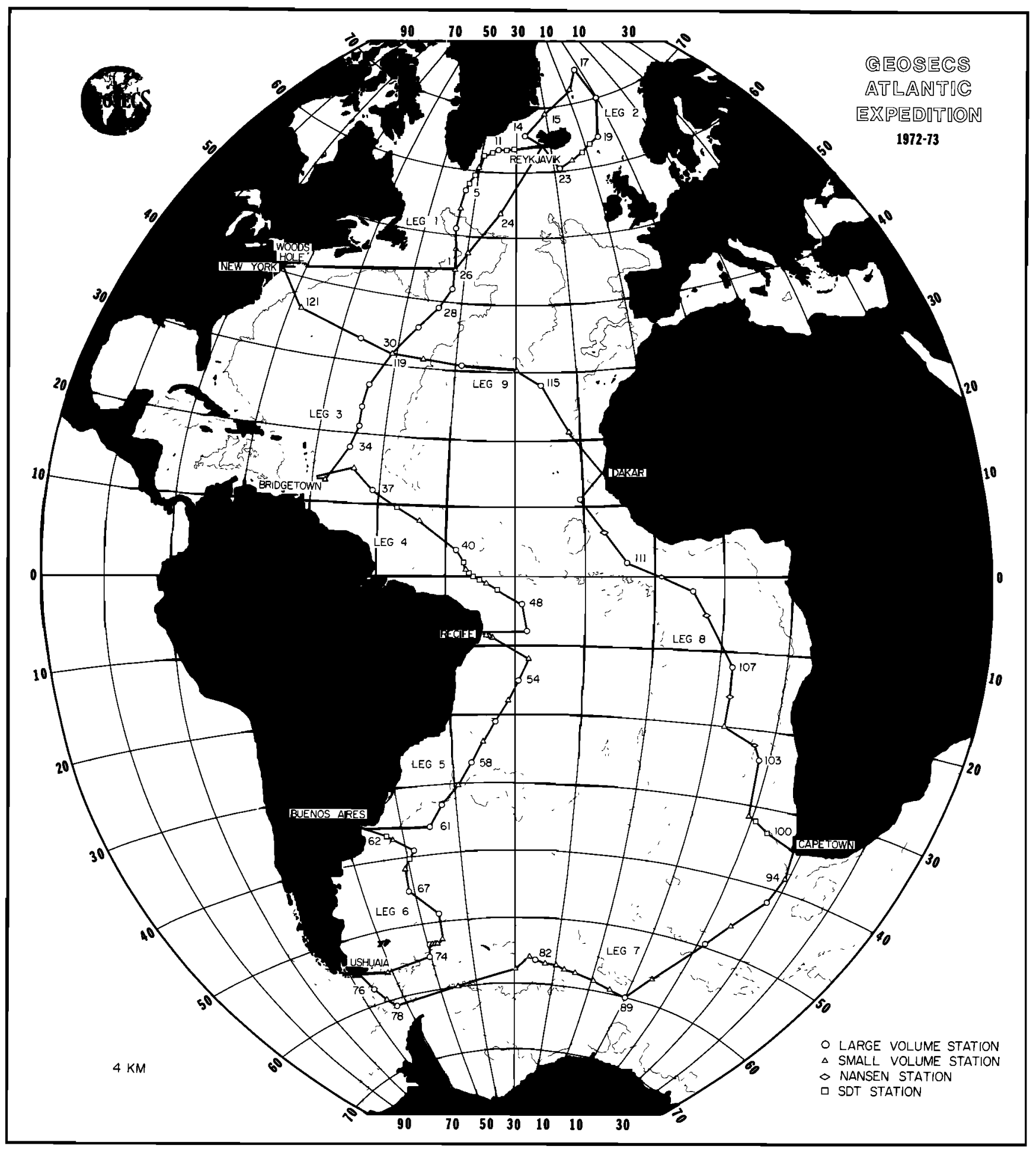

Fig. 1b. GEOSECS.

\section{Potential Density Surfaces}

We shall briefly review the potential density surfaces chosen by Sarmiento et al. [1982a] which are also adopted here. Figure 2 shows the position of wintertime outcrops, and Figure 3 shows the depths of the surfaces. The shallowest surface, $\sigma_{\theta}=25.6$, outcrops in the region of subtropical Ekman convergence in the North Atlantic and is the core of the high-salinity, high-oxygen Subtropical Underwater tongue that extends from the subtropics toward the equator [Wor- thington, 1976]. In the South Atlantic this surface outcrops mostly in the region of convergence, but the line of outcropping runs northeastward until it enters the region of Ekman divergence in the easternmost tropical South Atlantic. This surface outcrops at much lower latitude in the South Atlantic than any of the other surfaces in this study, and this is reflected in the relatively high-salinity value of the southern source water for this surface.

The next four surfaces outcrop, at least partially, in the region of Ekman convergence in the North Atlantic; hence we 


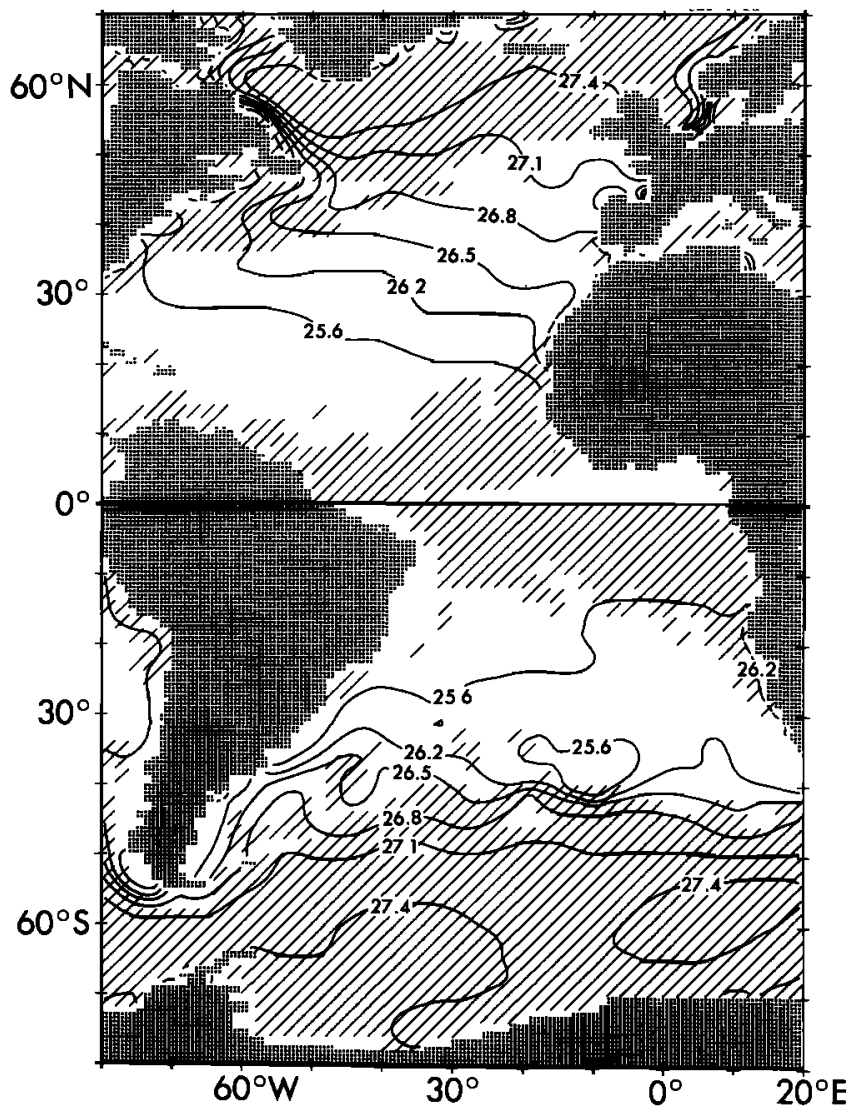

Fig. 2. Lines of wintertime outcrops for the six layers. These were determined from the ocean atlas by Levitus [1982]. Cross-hatched areas are regions of Ekman suction (upwelling) in winter, as determined from wind stress data of Hellerman and Rosenstein [1983].

expect direct injection of water into these surfaces from the outcrop. These are $\sigma_{\theta}=26.2,26.5,26.8$, and 27.1. In the South Atlantic they all outcrop in the circumpolar front, which coincides with the line of zero wind stress curl. The $\sigma_{\theta}=26.5$ surface is the lower bound for $18^{\circ}$ water in the North Atlantic [Worthington, 1959], while $\sigma_{\theta}=27.1$ is the level where the subpolar mode water of the North Atlantic is found [McCartney and Talley, 1982]. The deepest surface, $\sigma_{\theta}=27.4$, is the only one studied here that does not outcrop in the region of Ekman convergence in either the southern or northern hemisphere. This surface lies within the tongue of the Antarctic Intermediate Water (AAIW), and the upper portion of the Mediterranean outflow. It also coincides with the nutrient maximum level in the northern subtropical gyre [Spencer, 1972].

\section{ObSERVATIONS}

\section{Salinity (Figure 4)}

A persistent feature of the salinity distributions on all six surfaces (Figure 4) is a salinity front that runs from Guyana in northern South America across the tropical North Atlantic to the western tip of Africa. The front divides high-salinity northern subtropical gyre waters from equatorial waters of lower salinity and is coincident with the North Equatorial Current. The cross-frontal salinity difference decreases from 1.2 to $0.5 \%$ as one descends the water column.

The water in the equatorial region is significantly fresher than the water in the northern or southern gyre on the $\sigma_{\theta}=$
25.6 surface. The equatorial water also appears to be slightly fresher than the gyre waters on the $\sigma_{\theta}=26.2$ and 26.5 surfaces. Farther down, large errors on the map associated with sparse data in the South Atlantic make it difficult to compare the South Atlantic with the rest of the ocean, but the nutrientsalinity plots (Figures $6 b, 7 b$, and $8 b$ ) indicate that equatorial waters are saltier than the South Atlantic source water.

Within the subtropical gyre, one sees a tongue of highsalinity water intruding from the outcrop line. The origin of the tongue is at the center of the gyre for the $\sigma_{\theta}=25.6$ surface, shifting eastward as one goes deeper. On the $\sigma_{\theta}=27.1$ surface the tongue has almost disappeared, but it is evident again on the $\sigma_{\theta}=27.4$ surface, this time originating not at the outcrop but off the Iberian Peninsula. For the shallower levels the tongue is caused by injection of salty surface waters of subtropical gyre from the outcrop, while for the deepest level it is a signal of the Mediterranean outflow. A second front is observed along the Gulf Stream separating fresh slope waters of the North American continent from the gyre water.

\section{Oxygen, AOU, Nitrate, Silica (Figures 5-8)}

These properties share many features in common, both in their spatial distributions and in their relation to salinity; hence they are discussed together. The salient features are well represented in the AOU maps and plots (Figure 6), with nitrate and silica (Figures 7 and 8, respectively) varying together with AOU, and oxygen (Figure 5) varying inversely with it. We thus discuss the AOU distribution first. Peculiarities of individual tracers are discussed afterwards.

AOU is high in the equatorial region and low in the northern subtropical gyre, with a front similar to that of salinity separating the two regions. However, a notable maximum in AOU occurs off Africa at all levels. The maximum grows in strength as one goes deeper, reaching its highest value at $\sigma_{\theta}=$ $27.1\left(>212.5 \mu \mathrm{mol} \mathrm{kg}{ }^{-1}\right)$. From this maximum a "ridge" of high AOU water extends westward at about $10^{\circ} \mathrm{N}$. A minimum in AOU can be seen at the equator just off the coast of Brazil except at $\sigma_{\theta}=27.4$, where this feature is totally absent.

North of the front, AOU diminishes to the outcrop. AOU levels are lower in the eastern basin for surfaces $\sigma_{\theta}=26.8$ and 27.1 , indicating either that the northern gyre is ventilated from the northeast, or that high-AOU waters from the equatorial region are being advected northward along the western boundary.

The property-property plots of AOU against salinity (Figure $6 b$ ) reveal the presence of cross-isopycnal and/or nonconservative processes. The northern source waters are significantly saltier than the southern source waters except on the $\sigma_{\theta}=25.6$ surface, where the two sources have essentially the same salinity. The AOU between the two "end-members" is well above the straight line joining them. The highest AOU values are in the maximum off Africa and the "ridge" extending from it along $10^{\circ} \mathrm{N}$. The $\sigma_{\theta}=25.6$ surface is anomalous in that the equatorial waters are distinctly fresher than either of the source regions in the North and South Atlantic. The $\sigma_{\theta}=$ 26.2 and 26.5 surfaces have equatorial waters of essentially the same salinity as the South Atlantic source water, but at $\sigma_{\theta}=$ 26.2 there are individual data points that feature waters that are fresher than the South Atlantic water. Since salt is a conserved quantity, the data indicate that there are sources of fresh water in these regions. As discussed later, it seems natural to postulate that upwelling is responsible for this feature. It also appears possible that the waters with the highest AOU 


\section{DEPTH $(m)$}
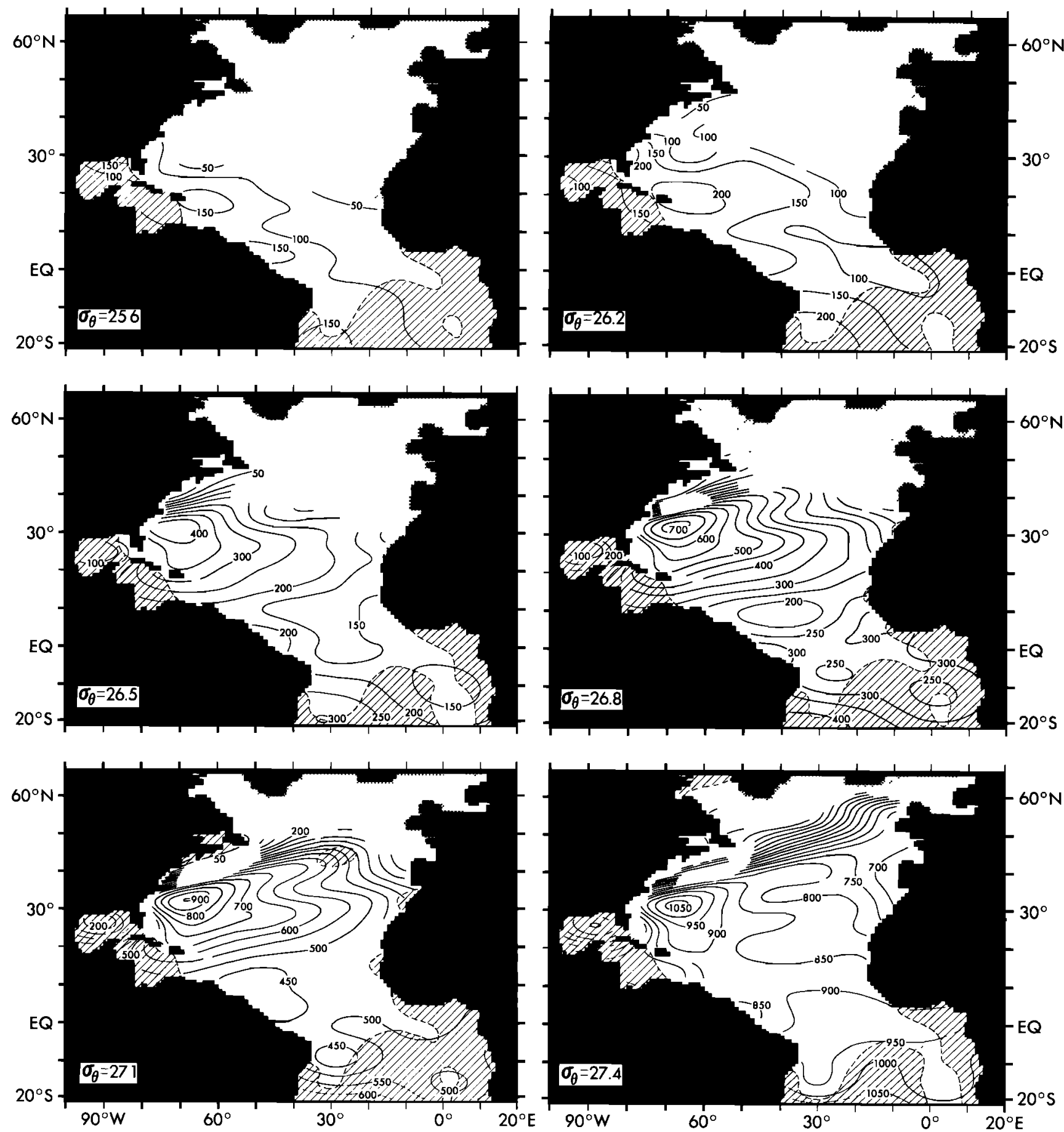

Fig. 3. Depth of the layers in meters. Stippled areas are where waters of this density are not present in wintertime (determined from the ocean atlas by Levitus [1982]). Cross-hatched areas are regions where the estimated error in depth is greater than $20 \mathrm{~m}$ for $\sigma_{\theta}=25.6,33 \mathrm{~m}$ for $\sigma_{\theta}=26.2,60 \mathrm{~m}$ for $\sigma_{\theta}=26.5,50 \mathrm{~m}$ for $\sigma_{\theta}=26.8,85 \mathrm{~m}$ for $\sigma_{\theta}=27.1,120 \mathrm{~m}$ for $\sigma_{\theta}=27.4$.

values on the plot for the $\sigma_{\theta}=26.5$ surface, which have low salinity values, are of local rather than South Atlantic origin.

The high AOU values of the deeper potential density surfaces can arise from consumption of oxygen on the density surface due to a high organic carbon particulate flux from the sea surface, or they can be an indication of a water type distinct from the northern and southern outcrop waters entering through cross-isopycnal advection and mixing.
Figure $6 b$ shows a branch composed of North American Slope Waters on the $\sigma_{\theta}=26.8$ surface and below and on the $\sigma_{\theta}=27.4$ surface a "tail" of high-salinity, low-AOU water of Mediterranean origin. Water from the northern outcrop on the $\sigma_{\theta}=27.4$ surface lies below the main mixing line between the northern gyre water and the South Atlantic water. Much of the outcrop water presumably belongs to the seasonal thermocline peculiar to the years in which the data were collected. 


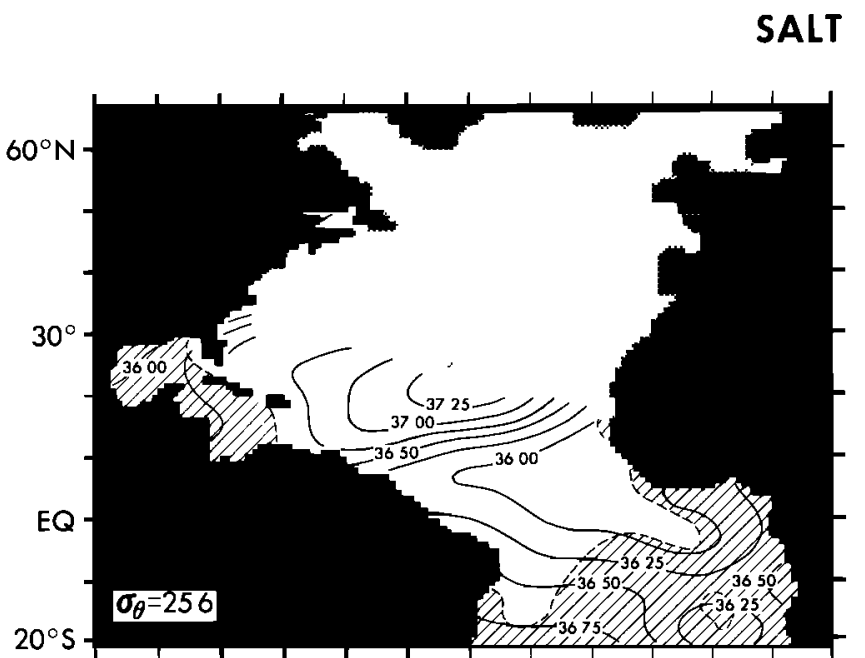

$(\% \circ)$
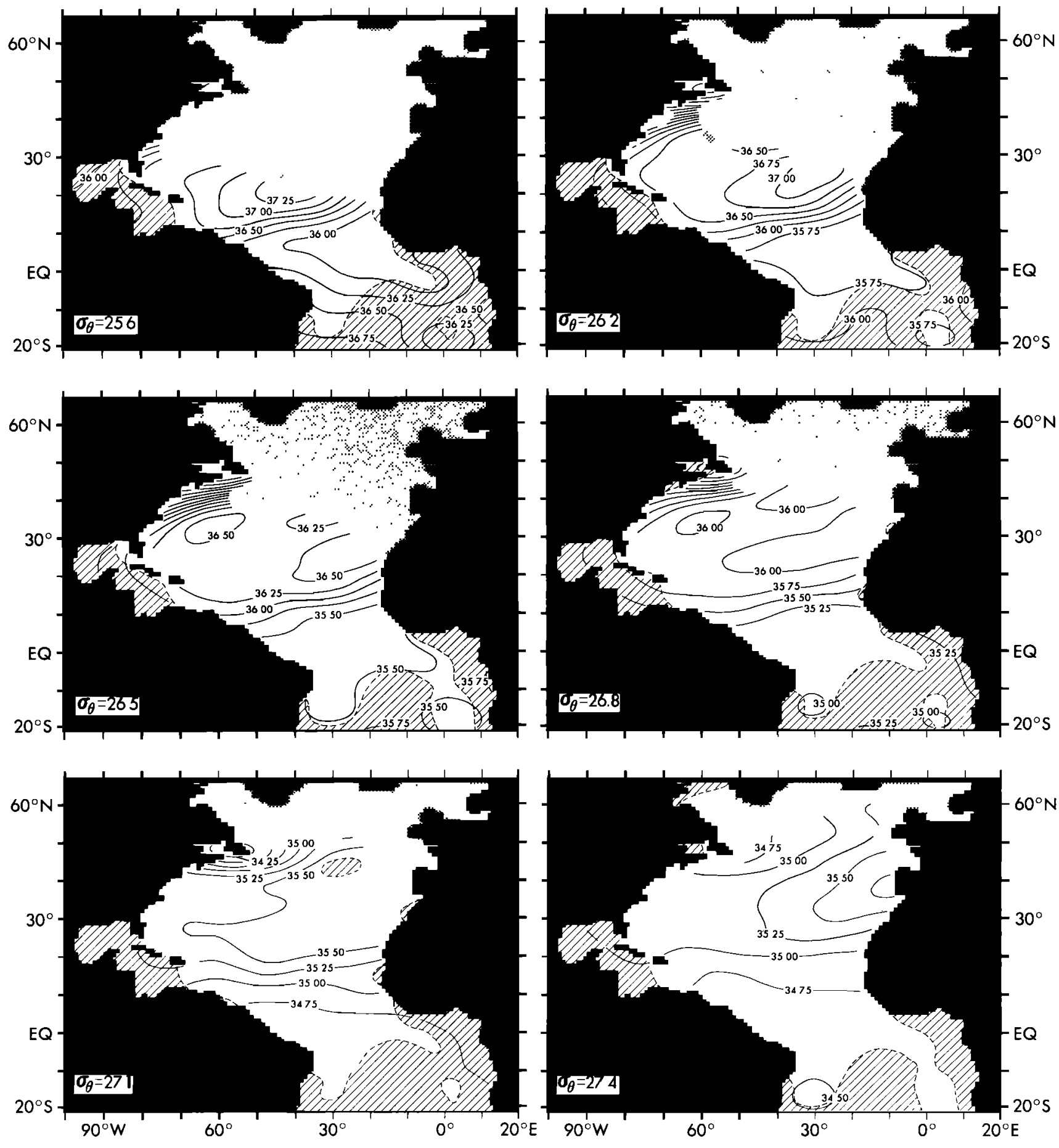

Fig. 4. Salinity in per mill. Stippled areas are as in Figure 3. Cross-hatched areas are regions with estimated error greater than $0.5 \%$ for $\sigma_{\theta}=25.6$ to 26.5 , and greater than $0.2 \%$ for the rest.

Also, waters from the Labrador Sea appear at the end of the slope water branch.

Nitrate maps and plots against salinity (Figure 7) show patterns very similar to those for AOU except that the nitrate concentration of South Atlantic source water increases as one goes deeper. This increase in nitrate for waters from the south has wiped out the equatorial minimum near Brazil on the $\sigma_{\theta}=27.1$ surface and even the African maximum at $\sigma_{\theta}=27.4$.

The increase of silica concentration of the southern source water is even more remarkable (Figure 8). Indeed, on the deepest surface, $\sigma_{\theta}=27.4$, the highest silica level occurs at the southernmost stations. Silica differs from AOU in several other aspects. The African maximum is not as strong as for AOU even when it is present, and a stronger maximum is seen farther to the west centered at about $37^{\circ} \mathrm{W}$ at $\sigma_{\theta}=26.2$. From the $\sigma_{\theta}=26.8$ surface downward, the position of the silica maximum shifts southward. At $\sigma_{\theta}=26.8$ it is at the equator, while at $\sigma_{\theta}=27.1$ it occurs outside the region of our mapping, in the 


\section{$\mathrm{O}_{2}\left(\mu \mathrm{M} \mathrm{k \textrm {kg } ^ { - 1 } )}\right.$}
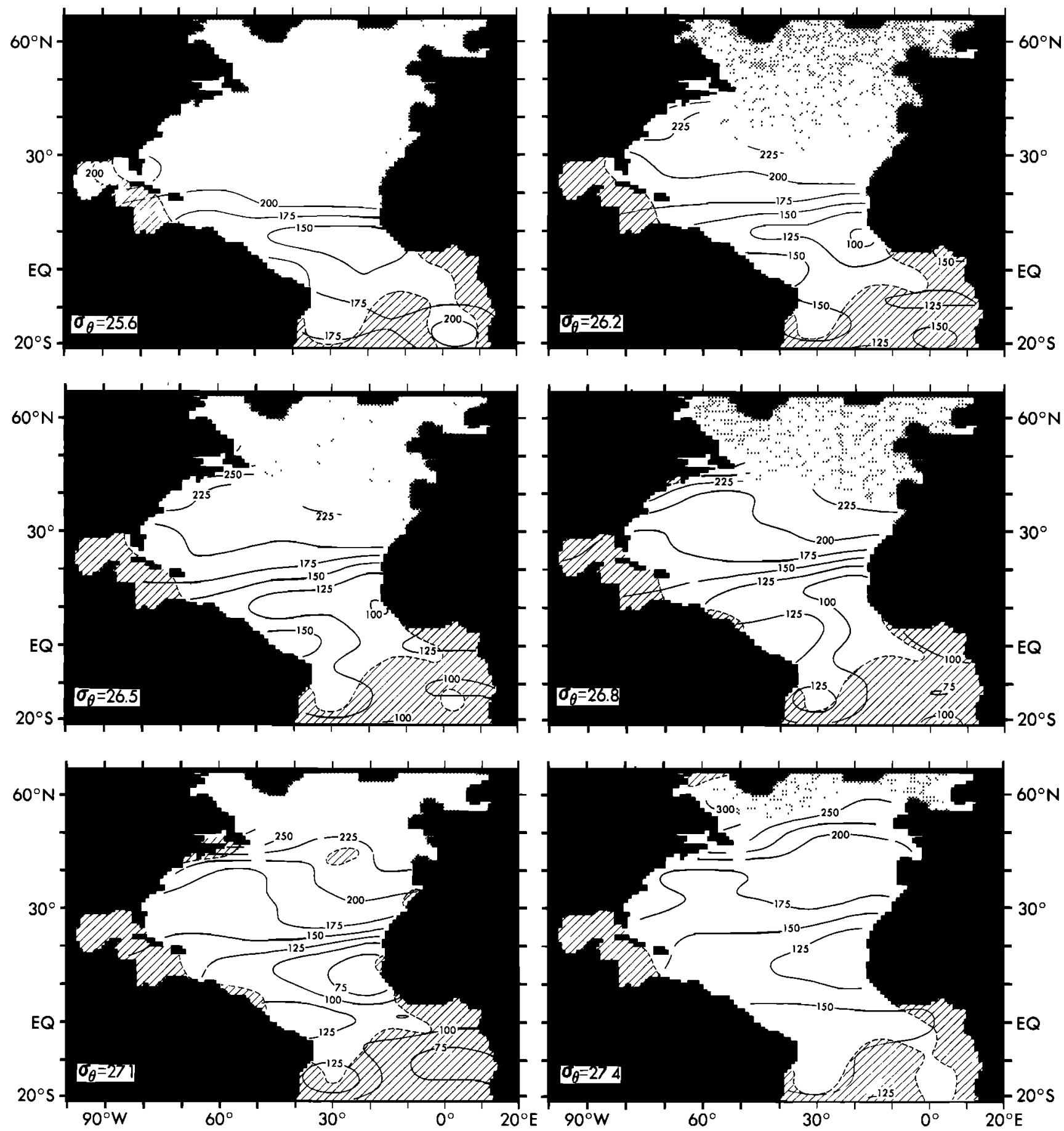

Fig. 5. Oxygen in micromoles per kilogram. Stippled areas are as in Figure 3. Cross-hatched areas are regions with estimated error greater than $25 \mu \mathrm{mol} \mathrm{kg}^{-1}$.

eastern South Atlantic at about $25^{\circ} \mathrm{S}$ (the point with the highest silica value on Figure $8 b$ is GEOSECS station 103 at $24^{\circ} \mathrm{S}$ ). As remarked earlier, on the deepest surface, $\sigma_{\theta}=27.4$, the highest silica level occurs in the southern source region. Moreover, the main mixing line features a slightly downward bend, indicating that silica is depleted from the value expected from straight-line mixing of the northern and southern waters. This feature indicates entry of a distinct water mass into this level in the tropics and will be discussed below in some detail.

\section{Discussion}

\section{Upwelling and Regeneration}

At $\sigma_{\theta}=25.6$ and 26.2 the freshest water occurs near the equator and off the African coast. Also, some stations in the equatorial region show waters with $\sigma_{\theta}=26.5$ that are as fresh as the freshest of the South Atlantic waters with this density. This water seems to be supplied through upwelling of deeper waters. High nutrient and AOU values for this fresh water 


\section{$\operatorname{AOU}\left(\mu \mathrm{M} \mathrm{kg^{-1 } )}\right.$}
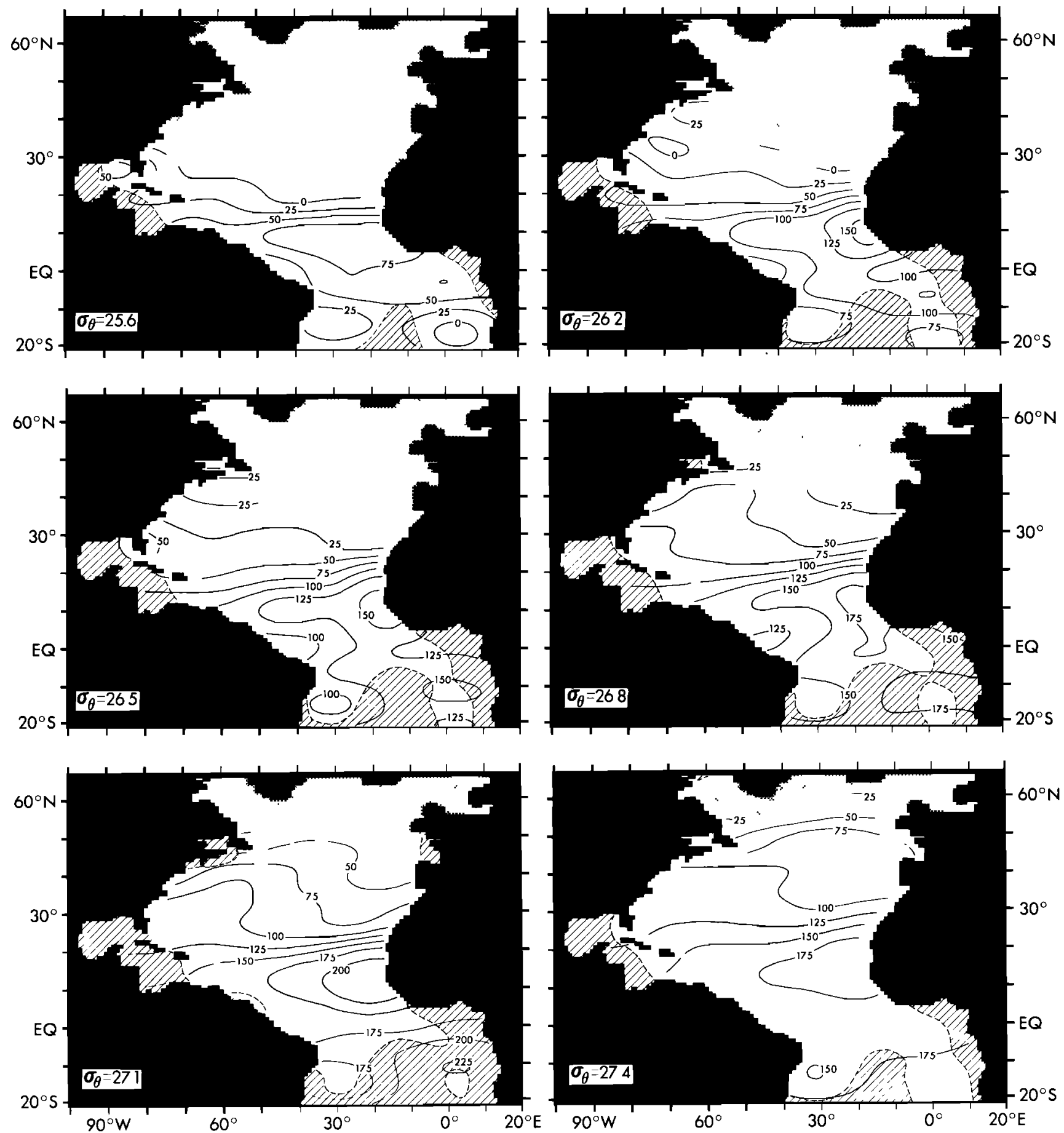

Fig. 6a. AOU in micromoles per kilogram. Stippled areas are as in Figure 3. Cross-hatched areas are regions with estimated error greater than $25 \mu \mathrm{mol} \mathrm{kg} \mathbf{~}^{-1}$.

seem to rule out the possibility that this fresh water enters from the surface ocean in the region of the Intertropical Convergence Zone.

Upwelling leads to exposure of high nutrient water to sunlight. Hence regions of upwelling are also regions of high productivity and, consequently, of high organic particulate fallout from the surface into the deeper ocean. As the dead organisms sink, they are decomposed by bacterial action, and nutrients are regenerated back into the ocean water. Hence underneath a region of upwelling one expects to see regions of high nutrient values. This is quite evident in our maps and plots. In particular, the upwelling off the West African coast has a great influence on the field of oxygen and nutrients (Figures 5-8). Note that this region of low oxygen/high nutrient water extends westward. This extension is coincident with the North Equatorial Current. The highly productive surface area, as 


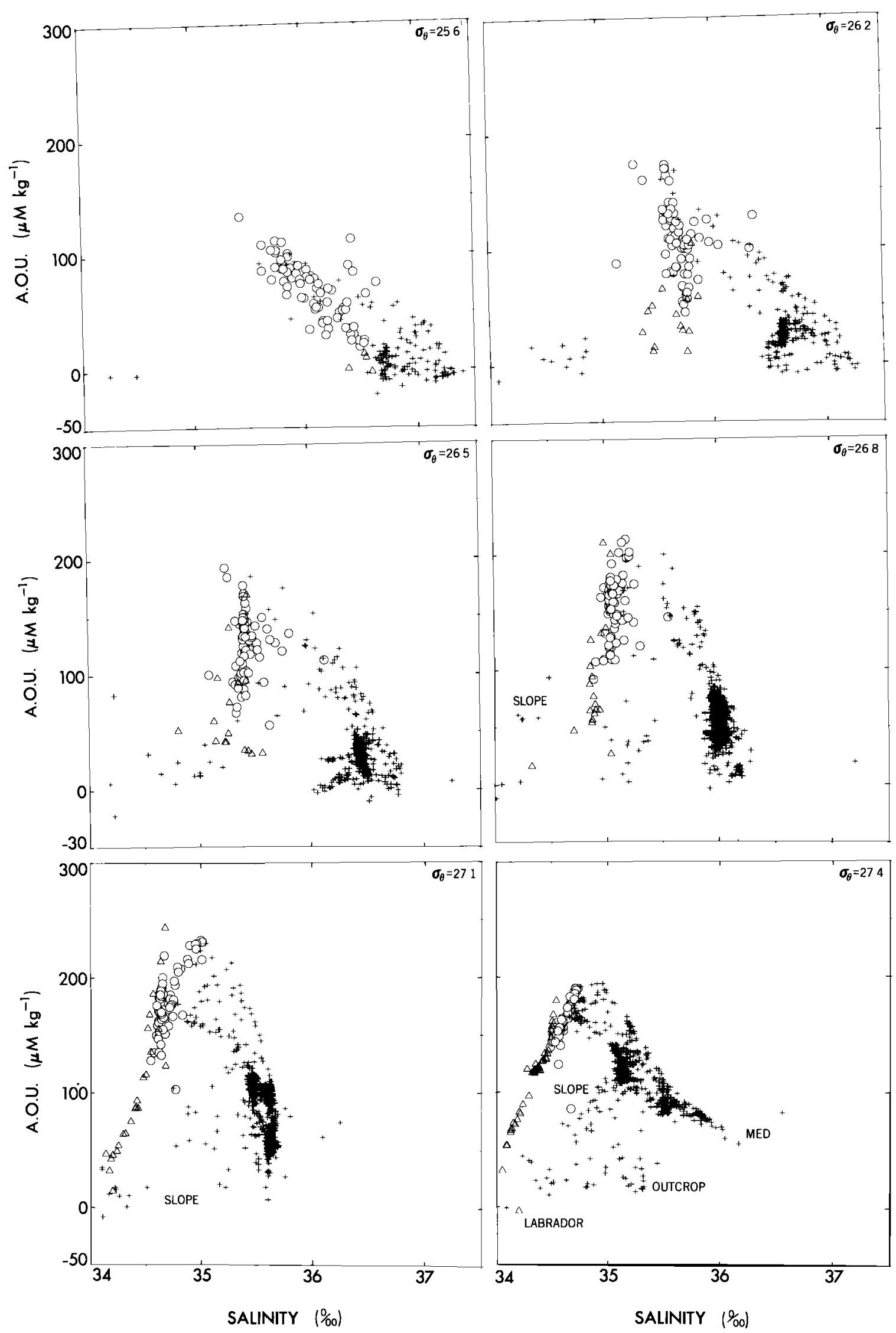

Fig. 6b. Salinity versus AOU. Crosses denote stations north of $10^{\circ} \mathrm{N}$, circles between $10^{\circ} \mathrm{N}$ and $10^{\circ} \mathrm{S}$, and triangles south of $10^{\circ} \mathrm{S}$. 


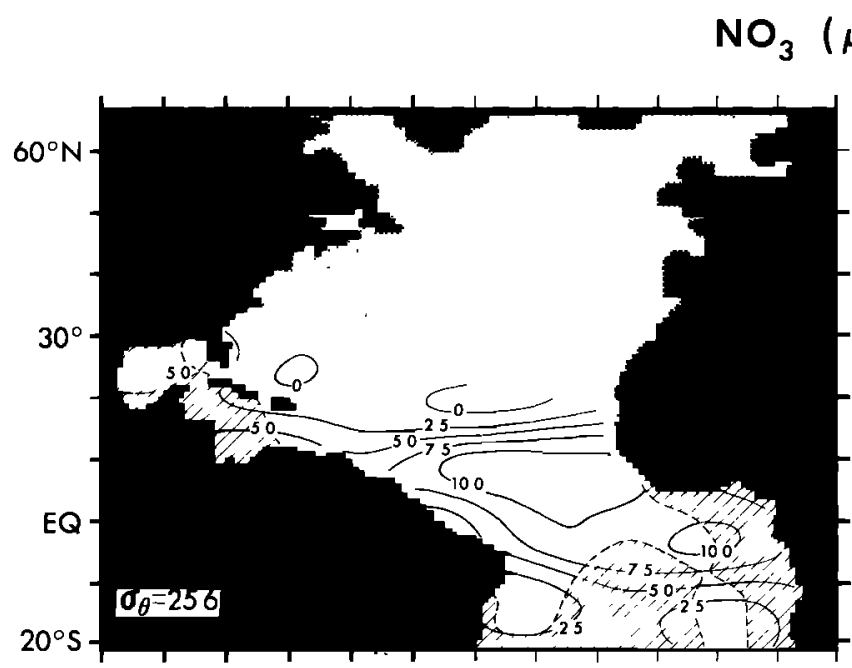

$\left(\mu \mathrm{M} \mathbf{k g}^{-1}\right)$
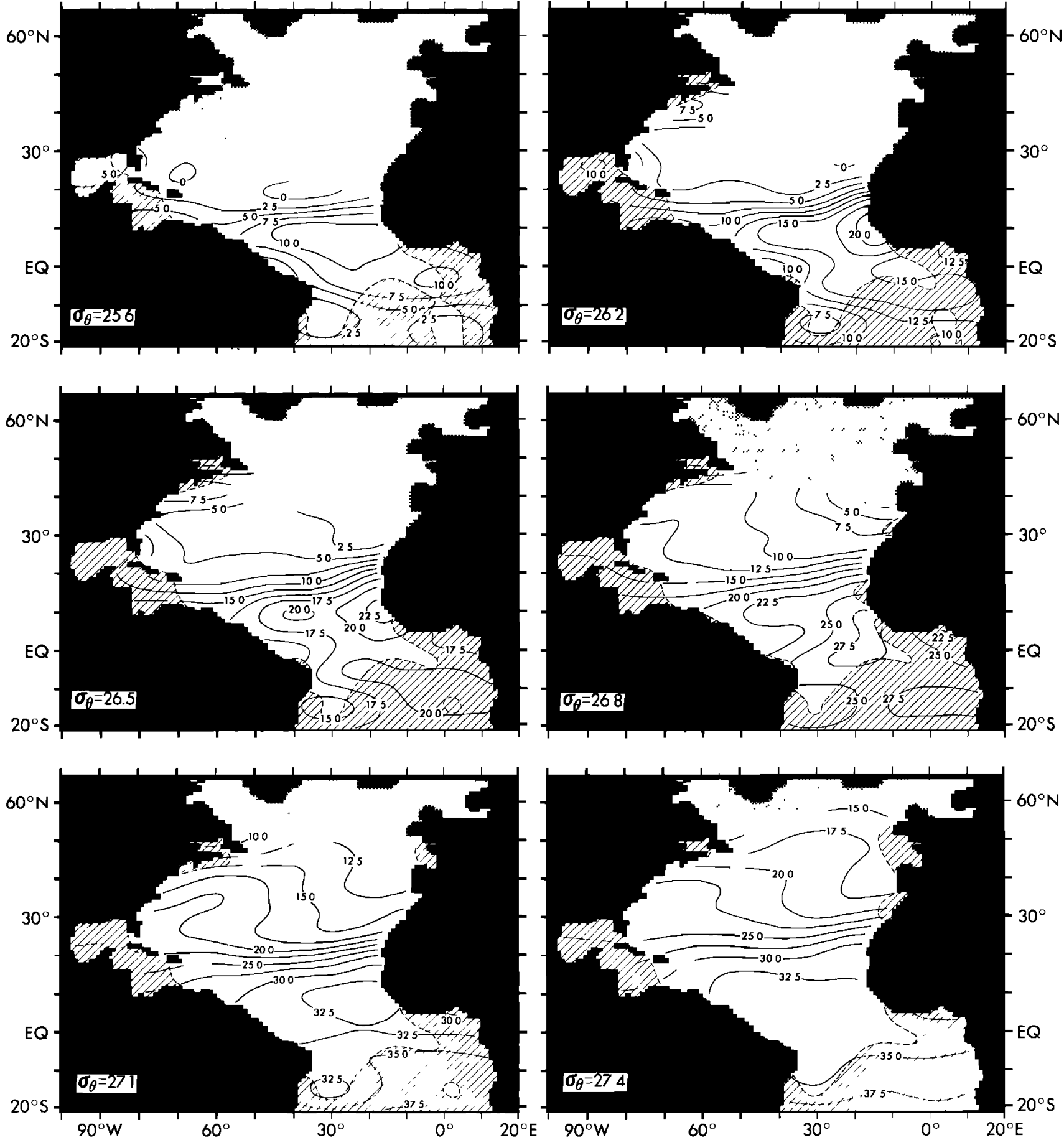

Fig. 7a. Nitrate in micromoles per kilogram. Stippled areas are as in Figure 3. Cross-hatched areas are regions with estimated error greater than $1.5 \mu \mathrm{mol} \mathrm{kg}{ }^{-1}$ for $\sigma_{\theta}=25.6,2.5 \mu \mathrm{mol} \mathrm{kg}^{-1}$ for $\sigma_{\theta}=26.2$ to 26.8 , and $3 \mu \mathrm{mol} \mathrm{kg}^{-1}$ for $\sigma_{\theta}=27.1$ and 27.4 .

well as perhaps some of the nutrient-rich water that underlies it, seems advected westward to form a conspicuous maximum in the nutrient concentration.

It is difficult to tell from nutrient data alone exactly what depth the upwelling water comes from, since upwelling, which brings up nutrient-rich waters of the deep, and regeneration of falling organic material which is abundant in the upwelling region similarly contribute toward an increase in the nutrient level on an isopycnal surface. In order to separate the signal of upwelling from that of regeneration we require a much more sophisticated knowledge of the regeneration process than we currently possess, especially that of the "Redfield ratio" that is crucial in separating independent information in each nutrient tracer. At present, one requires other tracers, such as carbon 14 , to achieve the separation of upwelling signal from that of regeneration. Broecker et al. [1978] and Wunsch [1984a] have attempted to estimate the rate of equatorial upwelling in the Atlantic using the GEOSECS carbon 14 data. Broecker et al. 

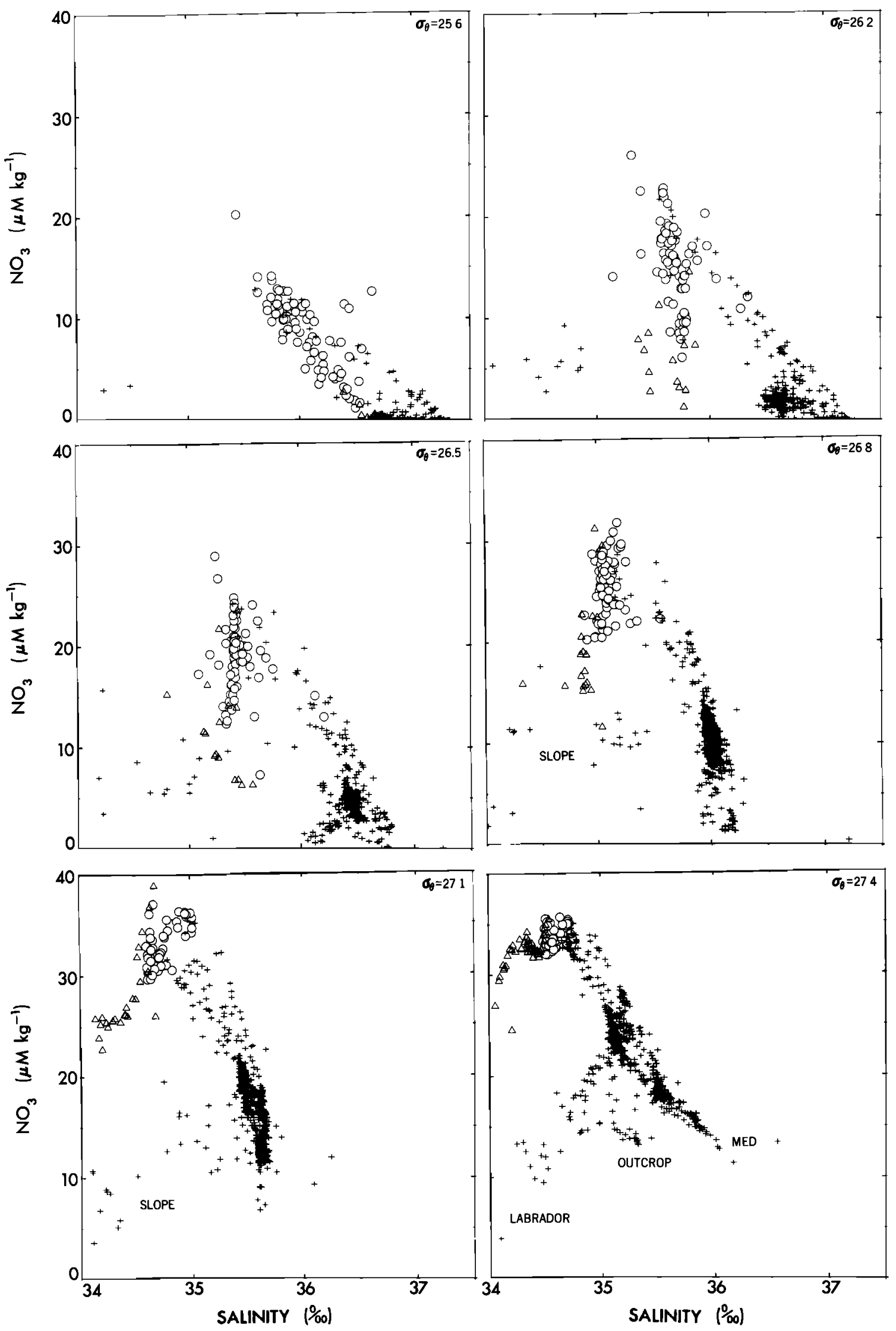

Fig. $7 b$. Salinity versus nitrate. For symbols, see Figure $6 b$. 
$\mathrm{SiO}_{2}\left(\mu \mathrm{M} \mathrm{kg} \mathbf{k g}^{-1}\right)$
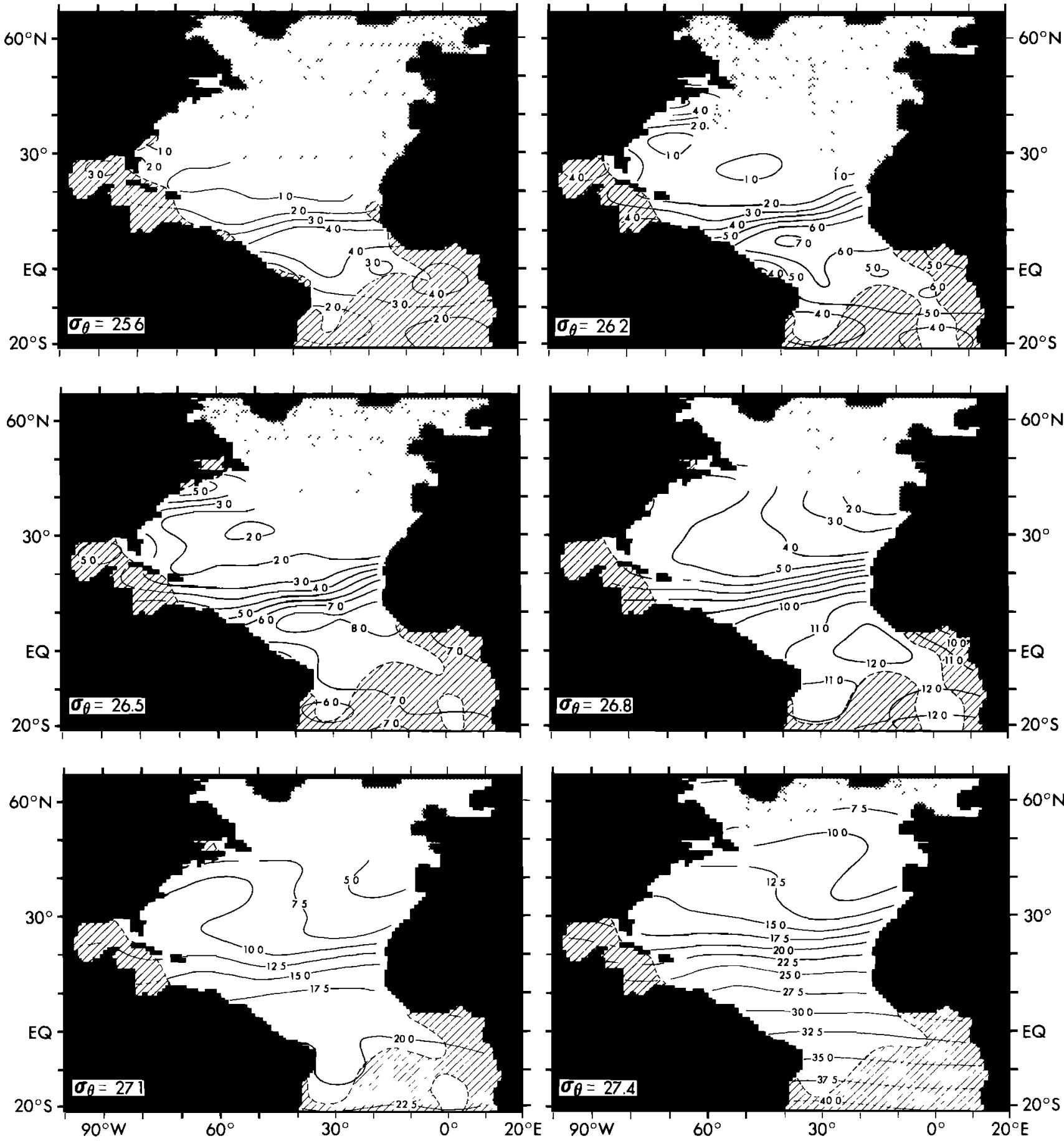

Fig. 8a. Silica in micromoles per kilogram. Stippled areas are as in Figure 3. Cross-hatched areas are regions with estimated error greater than $0.5 \mu \mathrm{mol} \mathrm{kg}{ }^{-1}$ for $\sigma_{\theta}=25.6,1 \mu \mathrm{mol} \mathrm{kg} \mathbf{~ g o r}^{-1} \sigma_{\theta}=26.2$ and $26.5,1.5 \mu \mathrm{mol} \mathrm{kg}^{-1}$ for $\sigma_{\theta}=26.8$, and $2.5 \mu \mathrm{mol} \mathrm{kg}{ }^{-1}$ for $\sigma_{\theta}=27.1$ and 27.4 .

hypothesized that upwelling originates at least as deep as 250 $m$ in their one-dimensional (vertical) steady state advectiondiffusion model calculation. Our salinity data indicate that upwelling penetrates at least down to $\sigma_{\theta}=26.2(100-150 \mathrm{~m}$ at the equator) and possibly to $\sigma_{\theta}=26.5$ (maximum depth 200 $\mathrm{m})$ and below. Wunsch used his "eclectic" model [Wunsch, $1984 b$ ] based on the IGY hydrography. Wunsch's model, which maximizes the calculated upwelling rate, shows a com- plex cellular pattern of circulation in the zonally integrated transport at the equator. It is not clear in his model at what depth upwelling originates. However, the facts that his upwelling estimate is small (maximum of $10 \mathrm{~Sv}\left(1 \mathrm{~Sv}=10^{6} \mathrm{~m}^{3} \mathrm{~s}^{-1}\right)$ compared with 17-27 Sv according to Broecker et al.) and that his surface boxes are thick (the bottom of the boxes are at $\sigma_{\theta}=26.5$ ) indicate that most of the upwelling may occur within the top $200 \mathrm{~m}$ of the ocean. 

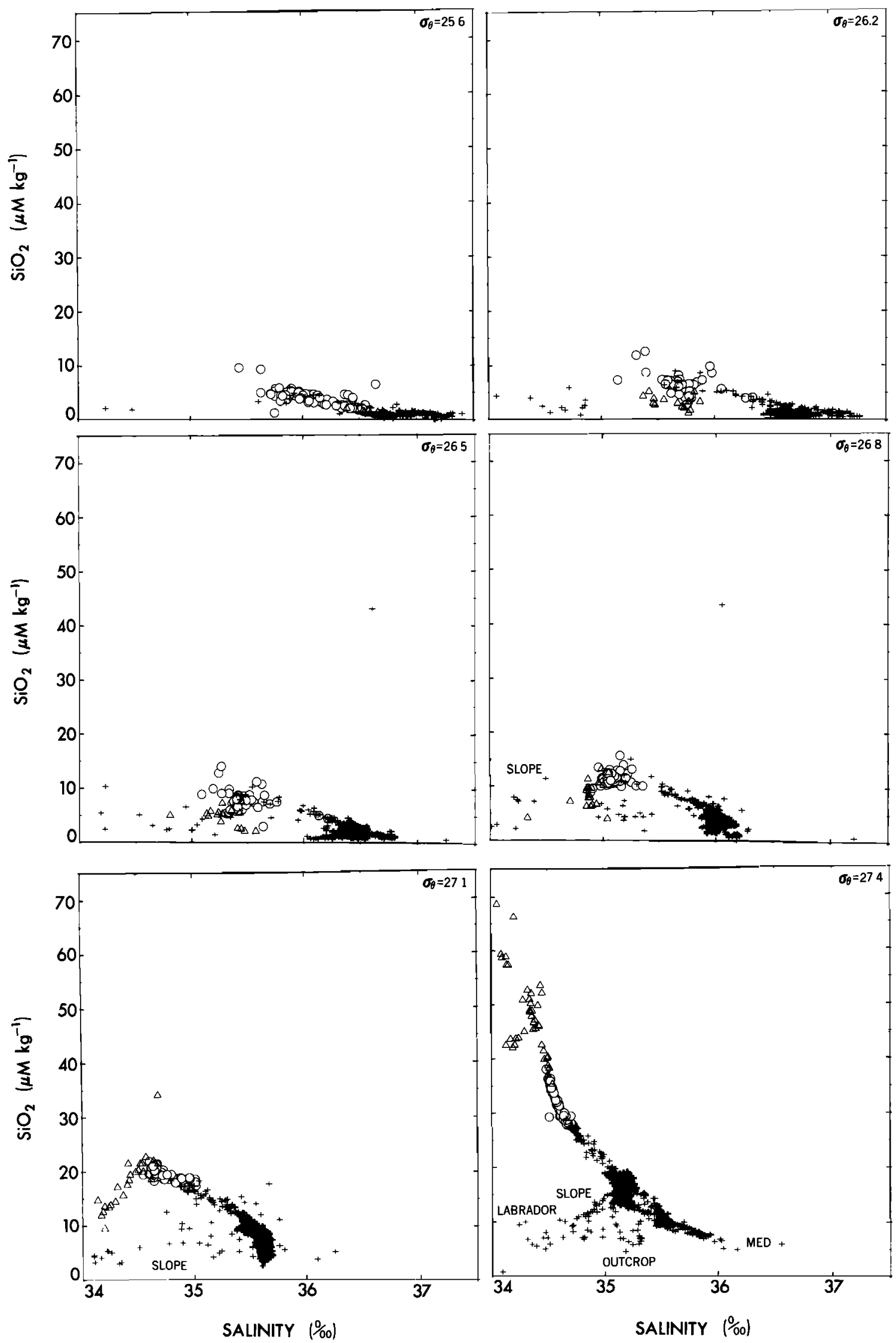

Fig. $8 b$. Salinity versus silica. For symbols, see Figure $6 b$. 


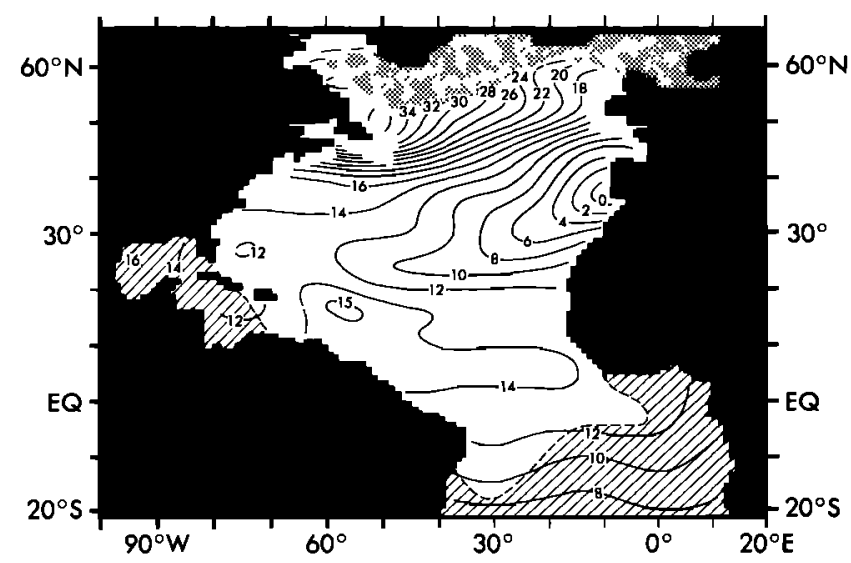

Fig. 9. Departure of silica, in terms of silica deficiency in micromoles per kilogram, from the value expected from straight mixing of the Antarctic water $\left(S=34.36 \%\right.$, $\left.[\mathrm{Si}]=52.06 \mu \mathrm{mol} \mathrm{kg}^{-1}\right)$ and the Mediterranean water $\left(S=35.86 \%\right.$, [Si] $\left.=7.55 \mu \mathrm{mol} \mathrm{kg} \mathbf{~ g}^{-1}\right)$ on $\sigma_{\theta}=$ 27.4. Cross-hatched areas are areas of large expected silica error (see Figure 8a). Stippled areas are as in Figure 3.

\section{Ventilation of the Northern Gyre}

Theories of the subtropical thermocline that have been developed in recent years [Rhines and Young, 1982; Young and Rhines, 1982; Luyten et al., 1983; Pedlosky and Young, 1983] distinguish three parts of different dynamical character in the subtropical gyre region. In the western basin there is the "recirculating" gyre that is distinguished by homogenization of potential vorticity [see Sarmiento et al., 1982a; McDowell et al., 1982]. To the east of this is the ventilated thermocline with direct connection to the surface water, and to the south east of the ventilated region is the "shadow" region of more stagnant waters. The distribution of AOU and nutrients supports this picture of subtropical thermocline circulation.

For levels $\sigma_{\theta}=26.5$ to 27.4 , one sees a tongue of low-AOU, low-nutrient water originating in the eastern part of the outcrop, extending southwestward. This tongue indicates the "ventilated thermocline," showing that the younger waters are coming into the layer from the northeast. This is also in agreement with the tritium data, which show a similar tongue on these potential density surfaces [Sarmiento et al., 1982a]. To the west of this tongue is a region of fairly weak property gradients, which corresponds with the recirculating gyre.

The southern side of the ventilated region is bordered by the sharp front in all nutrients mentioned above. To the southeast of this is the region of very high nutrient levels and low oxygen levels. It seems natural to identify this region with the "shadow" region of the scheme of Luyten et al. [1983]. As argued by Wyrtki [1962], the presence of biological consumption coupled with stagnation of water produces regions of low oxygen level and high regenerated nutrient level. Thus the front signifies the boundary of the shadow region, and the contrast between the younger waters of the ventilated thermocline and older waters in the shadow region is no doubt enhanced by the strong regeneration in the latter region.

We also note that the level $\sigma_{\theta}=27.4$ shows a tongue of high-oxygen, low-nutrient water from the northeast, although the climatological wind and hydrographic data suggest that this layer is not directly ventilated through Ekman pumping. Presumably, intermittent Ekman pumping due to variations in the wind field and/or sea surface temperature variations with consequent shift in the position of the outcrop can still inject surface water directly into this layer.

\section{Silica Deficiency in the Tropics}

Broecker and Ostlund [1979] report a "bend" on the main mixing line on plots of silica and "PO" $\left([\mathrm{PO}]=\left[\mathrm{O}_{2}\right]+\right.$ $R_{\mathrm{PO}_{4}}\left[\mathrm{PO}_{4}\right]$ where $\boldsymbol{R}_{\mathrm{PO}_{4}}$ is the oxygen-phosphate Redfield ratio) against salinity, apparently situated in the tropics, at the level $\sigma_{\theta}=26.8$. In our study this bend is again seen on the salinity versus silica plots, not only at but also below the level of $\sigma_{\theta}=26.8$. Particularly noteworthy is the downward bend (i.e., silica deficiency) that is seen in the salinity-silica plot at $\sigma_{\theta}=27.4$. Figure 9 shows the relative deficiency of silica on this surface compared with the level expected from straight mixing of the Mediterranean water and the South Atlantic source water under the assumption of no cross-isopycnal mixing. In the above-mentioned work, Broecker and Ostlund have suggested that the bend is due to either (1) enhanced cross-isopycnal mixing or (2) in situ regeneration of silica. While the latter can account for the silica excess at $\sigma_{\theta}=26.8$ and 27.1, it cannot explain the silica deficiency at the deepest level.

A concern that naturally arises is that this level, $\sigma_{\theta}=27.4$, is already quite deep (see Figure 3), and therefore a potential density surface with reference pressure of the sea surface may not be a good representation of the actual surface along which mixing takes place. To investigate this possibility, we produced salinity-silica plots on potential density surfaces with reference pressures ranging from 200 to 2000 dbar that coincide with the $\sigma_{\theta}=27.4$ surface at the equator. We found that as the reference pressure increases, the pattern on the plot rotates counterclockwise, but the bent shape of the mixing curve is maintained. Hence we believe that the bend is not an artifact of the choice of reference pressure. We argue that there is an entry of a different water mass from the northern or southern source waters into this level in the tropics. It can be due either to injection of a new type of water along the potential density surface which is not resolved in our data or to in situ cross-isopycnal mixing. The former seems unlikely, for since the data coverage is good in the northern and western tropical Atlantic, such water must come from the southeast. In view of the generally high silica values of the southern ocean, it is difficult to imagine entry of low-silica water, as evident in the bend, from the south. We argue that cross-isopycnal mixing is a more likely cause of this feature.

To ascertain the magnitude of cross-isopycnal mixing that is necessary to create such a deficiency, we conducted a simulation of the salinity-silica distribution on this potential density surface with a very simple phenomenological model for the potential density surface $\sigma_{\theta}=27.4$. The model is a onedimensional "pipe" model aligned along the potential density surface in the north-south direction, which pictures the Antarctic Intermediate Water as a northward moving slab of water. The configuration of the model is illustrated in Figure 10. In this model, addition of silica by regeneration was neglected. Regeneration of silica will counteract the removal of silica through cross-isopycnal mixing. Hence the mixing coefficient and/or cross-isopycnal velocity given by this model should be considered as possibly underestimated.

The local budgets of salinity and silica in this model are described by steady state advection-diffusion equations:

$$
\begin{aligned}
u S_{x}+w S_{z} & =\left(K S_{x}\right)_{x}+D S_{z z} \\
u[\mathrm{Si}]_{x}+w[\mathrm{Si}]_{z} & =\left(K[\mathrm{Si}]_{x}\right)_{x}+D[\mathrm{Si}]_{z z}
\end{aligned}
$$

where $u$ is the isopycnal velocity and $w$ is the cross-isopycnal velocity determined from equation (3) below. $K$ is the iso- 


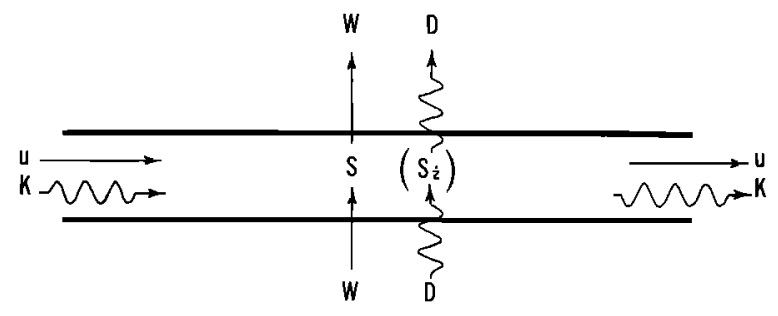

SOUTH

NORTH

Fig. 10. Configuration of the pipe model of the layer $\sigma_{\theta}=27.4$.

pycnal and $D$ the cross-isopycnal eddy-diffusion mixing coefficient. $S$ is salinity, and [Si] is silica concentration. The coordinate $x$ is taken along, and $z$ normal to, the isopycnal level. The subscript $x$ means the derivative with respect to $x$ with $z$ constant, and the subscript $z$, vice versa. In addition to this, from (1), and the conservation equation for potential temperature $\theta$, one can derive the following relation between crossisopycnal velocity and convergence of heat and salt fluxes due to mixing (see the appendix for the derivation):

$$
w \rho_{z}=\rho_{\theta} \theta_{s s} K\left(S_{x}\right)^{2}+D\left(\rho_{\theta} \theta_{z z}+\rho_{s} S_{z z}\right)
$$

where $\rho$ is the potential density and $\rho_{\theta}$ is the derivative of $\rho$ with respect to $\theta$ evaluated with $S$ fixed, $\rho_{s}$ with respect to $S$ with $\theta$ fixed, while $\theta_{s s}$ is the second derivative of $\theta$ in $S$ evaluated with $\rho$ fixed. This equation states that flux convergences of heat and salt alter the potential density of the water parcel, and consequently, the parcel leaves the original potential density surface. The first term on the right-hand side arises from nonlinearity in the equation of state for seawater. The $\theta_{s s}$ is always negative; hence this term is always positive. The resultant velocity is downward in a stably stratified water column. This effect is known as "cabelling." The second term on the right-hand side represents flux convergences of heat and salt due to cross-isopycnal mixing. The diffusive parameterization for cross-isopycnal mixing with the same diffusivity for both salt and heat does not apply to salt fingering, since salt fingers transport heat and salt at different rates. As is noted later, salt fingering does not seeem to be active on this layer.
Inputs for the model are the isopycnal velocity $u$, mixing coefficients $K$ and $D$, and cross-isopycnal derivatives that appear in equations (1)-(3). These derivatives are evaluated in each $5^{\circ}$ latitudinal band by fitting quadratic curves to the data in that band about the potential density level $\sigma_{\theta}=27.4$. These values were assigned at the center of the band and were linearly interpolated to points in between. The isopycnal velocity was set at $0.1 \mathrm{~cm} \mathrm{~s}^{-1}$. This value is consistent with the estimate by Riley [1951] that sets the cross-equatorial transport of water with potential densities between $\sigma_{\theta}=27.2$ and 27.4 to be $1.5 \mathrm{~Sv}$. A more recent calculation by $F u$ [1981] indicates that with IGY hydrography the transport in this layer is somewhere between 1 and $3 \mathrm{~Sv}$ (depending on the choice of level of no motion). However, Wunsch $[1984 a, b]$, using the same hydrography and his "eclectic" model of the Atlantic Ocean, found zero zonally integrated transport in the core of the Antarctic Intermediate Water (Circumpolar Intermediate Water in his terminology) level at the equator, with northward transport above and southward transport below it. It should be kept in mind that both the calculations of Fu and Wunsch are based on a quasi-synoptic hydrographic data set, and therefore their flow field may not be representative of the climatological average flow pattern which the nutrient field reflect. In particular, Wunsch's solutions are extremal in one oceanographic parameter or another (heat transport, equatorial upwelling) and are not necessarily the most likely state of the ocean as inferred from the data set. Since we are primarily interested in an order-of-magnitude estimate for the diffusivities, we take $u=0.1 \mathrm{~cm} \mathrm{~s}^{-1}$ to be a representative value.

The northern and southern boundaries were set at $22^{\circ} \mathrm{N}$ and $30^{\circ} \mathrm{S}$ respectively. Salinity and silica values were fixed at the boundaries to the observed values at these latitudes. The system of equations (1) (3) was solved iteratively for salinity, silica, and cross-isopycnal velocity $W$ with these boundary conditions for different values of $K$ and $D$. We sought the $K$ and $D$ values that gave realistic salinity and silica distributions.

An appropriate solution to the problem requires either that silica be reduced or that salinity be reduced, or both, relative

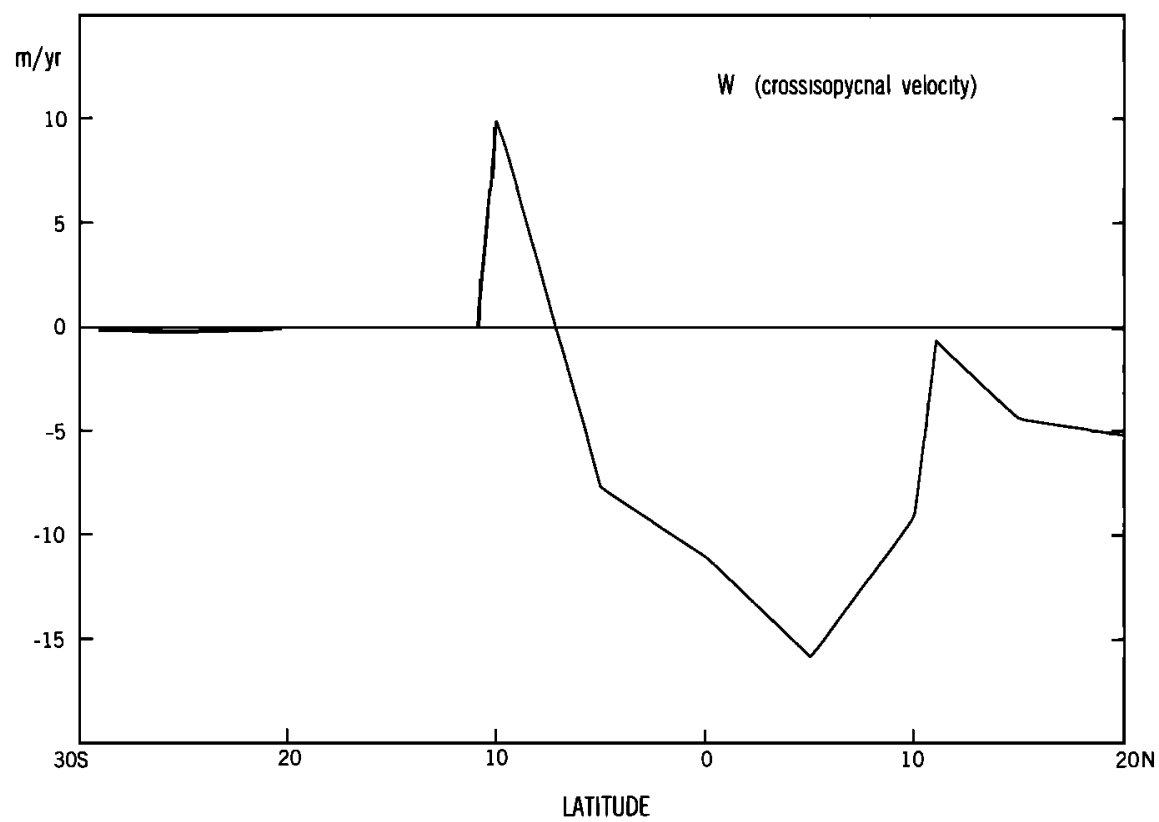

Fig. 11. Cross-isopycnal velocity at $\sigma_{\theta}=27.4$ as predicted by the model, for $K=3.2 \times 10^{7} \mathrm{~cm}^{2} \mathrm{~s}^{-1}, D=0.18 \mathrm{~cm}^{2} \mathrm{~s}^{-1}$. 
TABLE 1. The rms Differences Between Observation and Model Solution for Different Values of $K$ and $D$

\begin{tabular}{|c|c|c|c|c|c|c|c|c|c|c|}
\hline \multirow[b]{3}{*}{$\begin{array}{c}D \\
\mathrm{~cm}^{2} \mathrm{~s}^{-1}\end{array}$} & \multicolumn{10}{|c|}{$K, \mathrm{~cm}^{2} \mathrm{~s}^{-1}$} \\
\hline & \multicolumn{2}{|c|}{$1.0 \times 10^{7}$} & \multicolumn{2}{|c|}{$1.8 \times 10^{7}$} & \multicolumn{2}{|c|}{$3.2 \times 10^{7}$} & \multicolumn{2}{|c|}{$5.6 \times 10^{7}$} & \multicolumn{2}{|c|}{$1.0 \times 10^{8}$} \\
\hline & $\underset{\%}{\text { Salinity, }}$ & , Silicate, & $\underset{1}{\text { Salinity, }}$ & ${ }_{\mu \mathrm{mol} \mathrm{kg}}^{\text {Silicate }}$ & $\underset{\%_{0}}{\text { Salinity, }}$ & Silicate, & $\underset{1}{\text { Salinity }}$ & , Silicate, & $\underset{1}{\text { Salinity, }}$ & , Silicate, \\
\hline 1.00 & * & & $*$ & & 0.229 & 8.155 & 0.086 & 6.054 & 0.094 & 4.215 \\
\hline 0.56 & $*$ & & 0.260 & 4.862 & 0.116 & 3.629 & 0.075 & 3.087 & 0.125 & 2.998 \\
\hline 0.32 & 0.0301 & 3.127 & 0.168 & 2.122 & 0.070 & 1.866 & 0.098 & 2.157 & 0.142 & 2.584 \\
\hline 0.18 & 0.023 & 6.078 & 0.113 & 3.756 & 0.068 & 2.270 & 0.115 & 2.065 & 0.156 & 2.234 \\
\hline 0.1 & 0.180 & 7.899 & 0.085 & 4.970 & 0.074 & 2.853 & 0.126 & 2.017 & 0.162 & 2.136 \\
\hline 0.056 & 0.163 & 9.202 & 0.073 & 5.683 & 0.081 & 3.225 & 0.134 & 2.073 & 0.164 & 2.128 \\
\hline 0.032 & 0.136 & 9.253 & 0.067 & 6.089 & 0.089 & 3.226 & 0.137 & 2.110 & 0.167 & 2.105 \\
\hline
\end{tabular}

$K$ and $D$ were increased by the factor of fourth root of 10 from one value to the next.

*Denotes regions with unrealistic (e.g., negative salinity) solutions.

to the values that would be obtained by straight mixing of the source waters. The $\sigma_{\theta}=27.4$ surface lies just below the salt minimum and is coincident with the silica maximum. Therefore vertical mixing alone increases salinity while reducing silica and cannot give a satisfactory solution. The vertical advection, which is determined from the heat and salt balance (equation (3)), enters into the solution in a very subtle and important way.

Initially, we allowed the cross-isopycnal mixing to occur uniformly throughout the model. However, it became apparent that no satisfactory solution can be obtained in that case. For values of $K$ and $D$ that gave a realistic silica distribution the layer became too saline. Conversely, for a realistic salinity distribution the layer remained too high in silica. This was apparently due to large upwelling induced by the convergence of heat flux due to cross-isopycnal mixing in the subtropical South Atlantic. This upwelling brought waters with low silica concentration but with high salinity into the layer. To obtain a realistic solution, cross-isopycnal mixing had to be restricted to within $10^{\circ}$ of the equator, where the velocity field is primarily downwelling (see Figure 11). This downwelling, then, lowers the salt as well as the silica, thus giving a more realistic solution.

Table 1 shows goodness of fit for various values of $K$ and $D$ with the latter being finite only in the tropics. We obtained realistic solutions for both fields for $K \simeq 3 \times 10^{7} \mathrm{~cm}^{2} \mathrm{~s}^{-1}$, $D \simeq 0.2 \mathrm{~cm}^{2} \mathrm{~s}^{-1}$. Figure 12 shows the solution for $K=3.2$ $\times 10^{7} \mathrm{~cm}^{2} \mathrm{~s}^{-1}, D=0.18 \mathrm{~cm}^{2} \mathrm{~s}^{-1}$ in comparison with the observations. Note that the bend is realistically simulated.

In conclusion, the data contain a clear signal of existence of a water mass type that is distinct from the northern or southern source water. If this is due to in situ cross-isopycnal mixing, as assumed by this model, a mixing coefficient of reasonable magnitude $\left(\sim 0.2 \mathrm{~cm}^{2} \mathrm{~s}^{-1}\right)$ will account for the observed feature, but most of cross-isopycnal mixing must occur in the tropics. This results in a downwelling motion on both sides of the equator in the tropics. This is quite different from Wunsch's $[1984 a, b]$ model, where roll-like circulation cells were observed along the equator. His model predicts exactly zero transport of the Antarctic Intermediate Water across the equator where the model was constrained not to let this water go south. This seems to indicate that there may be a conflict between the quasi-synoptic hydrography, which may predict southward flow of the Antarctic Intermediate Water along the equator, and the model constraint, which dictates otherwise. The roll-like circulation in his model may well be a conse- quence of this conflict rather than a real feature of the equatorial circulation.

The value we obtained for cross-isopycnal mixing coefficient is by no means unexpected. However, note that our value for $u$ was derived assuming that the Antarctic Intermediate Water advances northward as a uniform slab of water. In reality, the Intermediate Water flow is probably concentrated at the western boundary as it crosses the equator [Wust, 1935; $F u, 1981]$. In that case, the diffusivities can be locally much greater in the boundary current than the above values.

The agent for this mixing is uncertain. One possibility is a Richardson number type instability induced by mean or transient shear current. That there are such shear currents in the deep equatorial ocean is well documented [e.g., Weisberg and Horigan, 1981], and they are also known to appear in detailed numerical models of the ocean that include the equator [Cox, 1980]. To consider this possibility, we looked at the equatorial Atlantic model of Philander and Pacanowski [1984] and also the Atlantic model of one of us (J.L.S.). Specifically, we looked at the Richardson number $R i=-g \rho_{z} \rho^{-1}(\partial u / \partial z)^{-2}$, where $g$ is the gravitational acceleration and $u$ is the speed of the horizontal flow, down to $1000 \mathrm{~m}$. Shear-induced mixing can be expected when the Richardson number becomes small compared to one [Pacanowski and Philander, 1981]. From both models it appears that the Richardson number is high $(\approx 10)$ for depths greater than $250 \mathrm{~m}$, which is not favorable for mixing. Hence the models indicate that there is not enough kinetic energy in the flow field at this depth to cause shearinduced mixing.

Another possible mechanism for mixing is salt fingering. Figure 9 shows that the greatest deficiency in silica occurs to the east of the Lesser Antilles. This area, where the salty Subtropical Underwater tongue lies above the fresh Antarctic Intermediate Water tongue, is thought to be a region of active salt fingering, although this occurs above $\sigma_{\theta}=27.4$ [Boyd et al., 1985]. In order to determine the likelihood of salt fingering, we looked at the distribution of the parameter $R_{\rho}$, defined as $R_{\rho}=-\alpha \Delta T / \beta \Delta S$, where $\alpha$ and $\beta$ are thermal and haline coefficients of density change and $\Delta T, \Delta S$ are changes in temperature and salinity in the vertical. Active salt fingering is expected when $R_{\rho}$ falls between one and about two [Schmitt, 1979]. We calculated $R_{\rho}$ from the Levitus ocean data to find that, except for a few small patches in the northern gyre, $R_{\rho}$ on this potential density surface is either well above 2 or below zero. This argues against salt fingering as a likely cause of the silica deficiency. We conclude that at this point the mecha- 


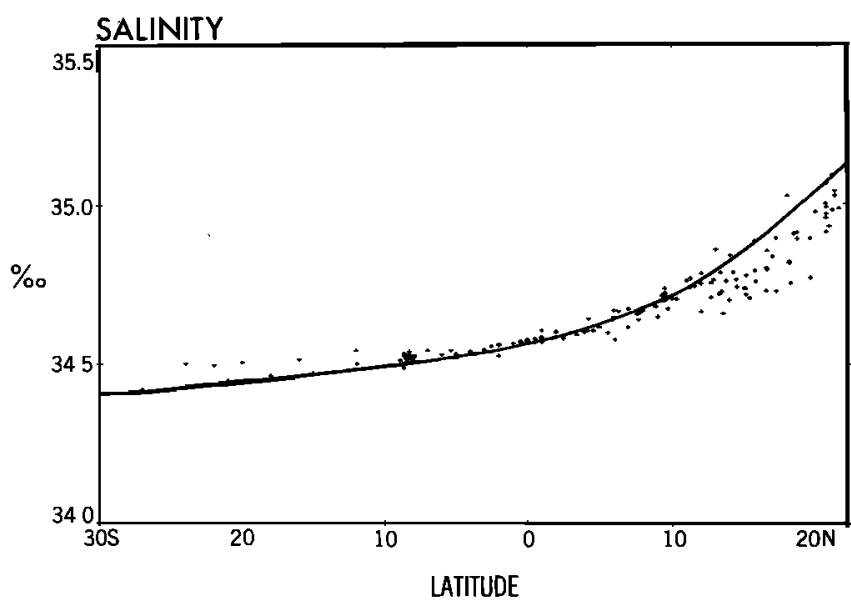

Fig. 12a. Salinity against latitude.

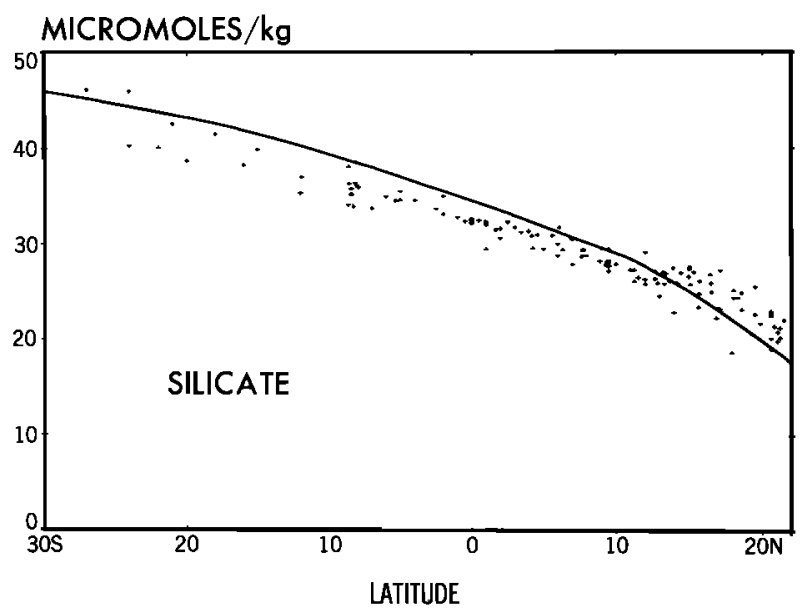

Fig. 12b. Silica against latitude.

SILICATE (micromole $/ \mathrm{kg}$ )

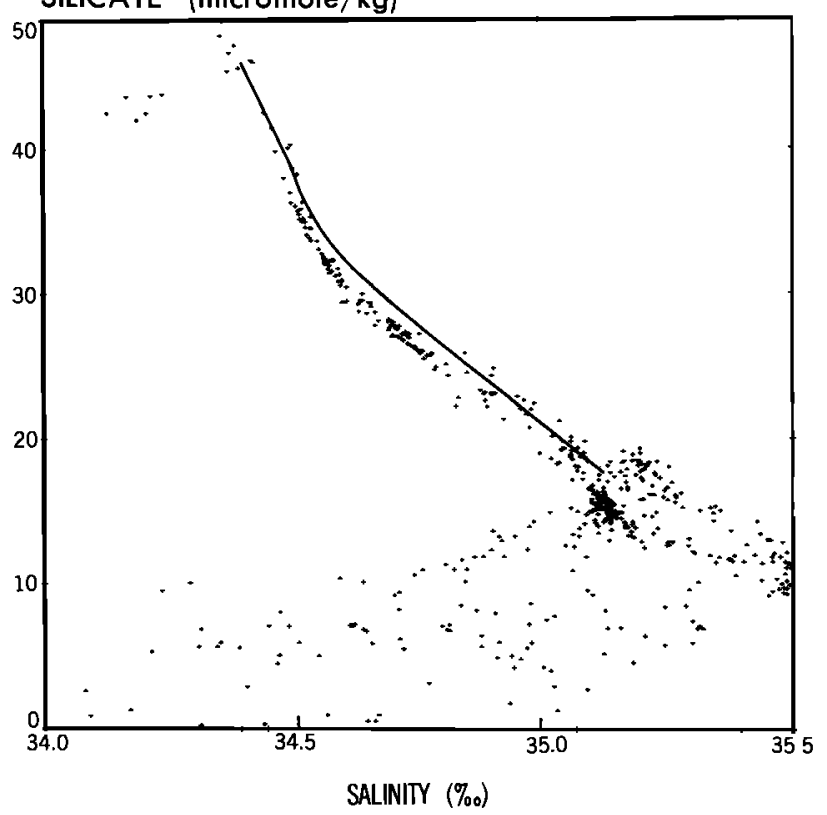

Fig. 12c. Silica against salinity.

Fig. 12. Comparison of the observed tracer fields and the model solution for $K=3.2 \times 10^{7} \mathrm{~cm}^{2} \mathrm{~s}^{-1}, D=0.18 \mathrm{~cm}^{2} \mathrm{~s}^{-1}$. Crosses denote observations. Bold lines denote model solution. nism for this mixing remains uncertain. It is hoped that further progress on our knowledge of equatorial dynamics and mixing processes in the ocean will solve this problem.

\section{Exchange With the Indian Ocean}

At $\sigma_{\theta}=27.1$, as we noted before, the highest level of silica occurs in the eastern South Atlantic near $25^{\circ} \mathrm{S}$. The level of silica there matches very well with that in the southern Indian Ocean GEOSECS data. It is at least possible that the two oceans share a common water source or there is an exchange of water, from Indian to Atlantic as well as the reverse. As argued by Gordon and Piola [1983], the export of the North Atlantic Deep Water from the Atlantic must be compensated by an inflow in the shallower layers into the Atlantic. A significant portion of this inflow can come from the Indian Ocean through advection and mixing of shear edge features on the Agulhas Current into the South Atlantic and through generation of warm-core rings in the Agulhas retroflection region which subsequently drift into the Atlantic [Lutjeharms, 1981 ; Piola and Gordon, 1984].

\section{Conclusion}

Our survey of Atlantic thermocline water shows that at these levels the Atlantic is predominantly a "two end-member" ocean with sources at the northern and southern outcrops. However, in addition to this, there are marginal water sources such as the Labrador Sea, the Mediterranean, and (possibly) the Indian Ocean. The equatorial region seems important in the water mass sense: for shallower levels, upwelling brings deeper waters in, while on the deepest level there is evidence of cross-isopycnal mixing in the form of deficiency of silica relative to salinity.

The presence of cross-isopycnal mixing creates problems for attempts to determine the Redfield ratios between oxygen and various nutrient elements from their dissolved values in the ocean water, since on an isopycnal surface one cannot readily distinguish cross-isopycnal transport from nonconservative processes. Takahashi et al. [1985] report a survey of TTO NAS, GEOSECS Atlantic Ocean and Indian Ocean data on two potential density surfaces $\sigma_{\theta}=27.0$ and 27.2 to determine these ratios. They point out that fitting a straight line on the oxygen versus nutrient plot and then calling the slope of the line the Redfield ratio is erroneous because of mixing of water masses with different preformed nutrient levels. They determine the preformed nutrient level at a given point by assuming that there is no cross-isopycnal mixing, and they subtract it from total nutrient concentration to obtain the regenerated portion from which they calculate the Redfield ratio. The resultant ratios are slightly different for the North Atlantic from that for the South Atlantic. The difference is not statistically significant in their study, but it may reflect the presence of cross-isopycnal mixing as evidenced in this study which will affect the level of preformed nutrient in the interior of the ocean rather than real regional variations in the Redfield ratio. Of course, the converse is possible, too: for example, since the definition of the theoretically conservative tracer "PO" depends on the Redfield ratio, the bend on the "PO" curve that was reported by Broecker and Ostlund [1979] may be due to nonuniform Redfield ratio rather than due to cross-isopycnal mixing. A more detailed study with the aid of observations of nonnutrient tracers and particulate matter will be necessary for unraveling the precise distribution of crossisopycnal mixing and possible regional variations in the Redfield ratios. 
Regeneration of nutrients and consumption of oxygen is active in the regions of upwelling, particularly off the western tip of Africa. This area of high regeneration also coincides with the "shadow region" of the thermocline where ventilation is poor, and this results in very high local levels of nutrients and low level of oxygen.

The detailed three-dimensional view of nutrient distributions afforded by the TTO and other data sets will be most valuable in putting constraints on possible modes of circulation in existing and future models of the ocean. One elementary example of this was provided in this paper where the salinity-silica distribution was used to provide information on cross-isopycnal advection and mixing. Also, nutrient cycles themselves are of serious modeling interest in relation to the climatic problems such as the magnitude of carbon dioxide uptake by the ocean. We believe that these new data sets are providing us with a firm basis with which we can compare and constrain the nutrient cycle models.

\section{Appendix: Derivation of Equation (3)}

Equation (3) of the main section relates cross-isopycnal flow to the density change of water parcel due to isopycnal and cross-isopycnal mixing. It is essentially the same as equation (4) of McDougall [1984] without the salt finger terms.

The balance equation for salt (equation (1)) is reproduced here:

$$
u S_{x}+w S_{z}=\left(K S_{x}\right)_{x}+D S_{z z}
$$

The balance equation for potential temperature is

$$
u \theta_{x}+w \theta_{z}=\left(K \theta_{x}\right)_{x}+D \theta_{z z}
$$

Note that derivatives with respect to $x$ are evaluated along an isopycnal: the potential density is held fixed. Hence we can substitute the expression

$$
\theta_{x}=\left.\frac{\partial \theta}{\partial S}\right|_{\rho} S_{x} \equiv \theta_{s} S_{x}
$$

into (A2). Equation (A2) becomes

$$
u \theta_{s} S_{x}+w \theta_{z}=\left(K \theta_{s} S_{x}\right)_{x}+D \theta_{z z}
$$

Expand the first term on the right-hand side:

$$
\left(K \theta_{s} S_{x}\right)_{x}=\theta_{s}\left(K S_{x}\right)_{x}+K S_{x}\left(\theta_{s}\right)_{x}
$$

and once again observe that $x$ derivative is evaluated with potential density fixed. Thus

$$
\left(\theta_{s}\right)_{x}=\theta_{s s} S_{x}
$$

and

$$
K S_{x}\left(\theta_{s}\right)_{x}=\theta_{s s} K\left(S_{x}\right)^{2}
$$

Hence (A2) is now

$$
u \theta_{s} S_{x}+w \theta_{z}=\theta_{s}\left(K S_{x}\right)_{x}+\theta_{s s} K\left(S_{x}\right)^{2}+D \theta_{z z}
$$

Multiply (A1) with $\theta_{s}$ and subtract from (A5) to get

$$
w\left(\theta_{z}-\theta_{s} S_{z}\right)=\theta_{s s} K\left(S_{x}\right)^{2}+D\left(\theta_{z z}-\theta_{s} S_{z z}\right)
$$

Note that

$$
\theta_{s}=-\left(\left.\frac{\partial \rho}{\partial S}\right|_{\theta}\right)\left(\left.\frac{\partial \rho}{\partial \theta}\right|_{s}\right)^{-1} \equiv-\frac{\rho_{s}}{\rho_{\theta}}
$$

and

$$
\rho_{z}=\left.\left.\frac{\partial \rho}{\partial \theta}\right|_{s} \frac{\partial \theta}{\partial z}\right|_{x}+\left.\left.\frac{\partial \rho}{\partial S}\right|_{\theta} \frac{\partial S}{\partial z}\right|_{x} \equiv \rho_{\theta} \theta_{z}+\rho_{\mathrm{s}} S_{z}
$$

Hence

$$
w \rho_{z}=\rho_{\theta} \theta_{s s} K\left(S_{x}\right)^{2}+D\left(\rho_{\theta} \theta_{z z}+\rho_{s} S_{z z}\right)
$$

which is equation (3) in the main section.

Acknowledgments. The authors would like to thank in particular C. Wunsch for sharing with us the Atlantis II cruise 109 data. They also thank S. Hellerman for producing the distribution maps, $\mathbf{M}$. Jackson for managing the data tapes, and R. Pacanowski for granting us access to his tropical Atlantic model. Discussions with and comments from K. Bryan, A. L. Gordon, R. M. Key, C. G. H. Rooth, W. Smethie, R. Stallard, T. Takahashi, and J. R. Toggweiler were most beneficial. The illustrations group at GFDL/NOAA, under P. Tunison, drafted the figures, and J. Callan typed the first draft. This research was sponsored by the ARL/NOAA grant NA83RAL00052, the NSF grants OCE8117846 and OCE8110155, and the DOE grant MM-19X-27405C.

\section{REFERENCES}

Boyd, J. D., H. Perkins, and K. D. Saunders, Hydrographic measurements off the northeast coast of South America, July, 1983, NORDA Tech. Note 305, 181 pp., Nav. Ocean Res. and Dev. Activ., NSTL, Miss., 1985.

Brewer, P. G., W. S. Broecker, W. J. Jenkins, P. B. Rhines, C. G. Rooth, J. H. Swift, T. Takahashi, and R. T. Williams, A climatic freshening of the deep Atlantic north of $50^{\circ} \mathrm{N}$ over the past 20 years, Science, 222, 1237-1239, 1983.

Broecker, W. S., and H. G. Ostlund, Property distributions along the $\sigma_{\theta}=26.8$ isopycnal in the Atlantic Ocean, J. Geophys. Res., 84, $1145-1154,1979$.

Broecker, W. S., and T. Takahashi, Hydrography of the central Atlantic, IV, Intermediate waters of Antarctic origin, Deep Sea Res., 28, $177-193,1981$.

Broecker, W. S., T.-H. Peng, and M. Stuiver, An estimate of the upwelling rate in the equatorial Atlantic based on the distribution of bomb radiocarbon, J. Geophys. Res., 83, 6179-6186, 1978.

Bryden, H. L., New polynomials for thermal expansion, adiabaitc temperature gradient and potential temperature of sea water, Deep Sea Res., 20, 401-408, 1973.

Cox, M. D., Generation and decay of 30-day waves in a numerical model of the Pacific, J. Phys. Oceanogr., 10, 1168-1186, 1980.

Fofonoff, N. P., Computation of potential temperature of seawater for an arbitrary reference pressure, Deep Sea Res., 24, 489-491, 1977.

$\mathrm{Fu}, \mathrm{L}$.-I., The general circulation and meridional heat transport of the subtropical South Atlantic determined by inverse methods, J. Phys. Oceanogr., 11, 1171-1193, 1981.

Gordon, A. L., and A. R. Piola, Atlantic Ocean upper layer salinity budget, J. Phys. Oceanogr., 13, 1293-1300, 1983.

Hellerman, S., and M. Rosenstein, Normal monthly wind stress over the World Ocean with error estimates, J. Phys. Oceanogr., 13, 1093-1104, 1983.

Ivers, W. D., The deep circulation in the northern North Atlantic, with especial reference to the Labrador Sea, Ph.D. thesis, Univ. of Calif., San Diego, La Jolla, 1975.

Levitus, S., Climatological atlas of the World Ocean, NOAA Prof. Pap. 13, U.S. Government Printing Office, Washington, D. C., 1982.

Lutjeharms, J. R. E., Features of the Southern Agulhas Current circulation from satellite remote sensing, S. Afr. J. Sci., 77, 231-236, 1981.

Luyten, J. L., J. Pedlosky, and H. Stommel, The ventilated thermocline, J. Phys. Oceanogr., 13, 292-309, 1983.

McCartney, M. S., and L. D. Talley, The subpolar mode water of the North Atlantic Ocean, J. Phys. Oceanogr., 12, 1169-1188, 1982.

McDougall, T. J., The relative roles of diapycnal and isopycnal mixing on subsurface watermass conversion, J. Phys. Oceanogr., 14, $1577-1589,1984$

McDowell, S., Analyses of North Atlantic intermediate waters along isopycnal surfaces and within mesoscale eddies, Ph.D. dissertation, Univ. of R. I., Kingston, 1982.

McDowell, S., P. Rhines, and T. Keffer, North Atlantic potential vorticity and its relation to the general circulation, J. Phys. Oceanogr., 12, 1417-1436, 1982. 
Montgomery, R. B., Circulation in upper layers of southern North Atlantic deduced with use of isentropic analysis, Pap. Phys. Oceanogr. Meteorol., 6(2), 55 pp., 1938.

Pacanowski, R. C., and S. G. H. Philander, Parameterization of vertical mixing in numerical models of tropical ocean, J. Phys. Oceanogr., 11, 1443-1451, 1981.

Pedlosky, J., and W. R. Young, Ventilation, potential vorticity homogenization and the structure of the ocean circulation, J. Phys. Oceanogr., 13, 2020-2037, 1983.

Philander, S. G. H., and R. C. Pacanowski, Simulation of the seasonal cycle in the tropical Atlantic Ocean, Geophys. Res. Lett., 11, 802804, 1984.

Piola, A. R., and A. L. Gordon, Pacific and Indian Ocean upper-layer salinity budget, $J$. Phys. Oceanogr., 14, 747-753, 1984.

Reid, J. L., and R. J. Lynn, On the influence of Norwegian-Greenland and Weddell seas upon the bottom waters of the Indian and Pacific oceans, Deep Sea Res., 18, 1063-1088, 1971.

Rhines, P. B., and W. R. Young, A theory of wind-driven circulation, I, Mid-ocean gyres, J. Mar. Res., 40, suppl., 559-596, 1982.

Riley, G. A., Oxygen, phosphate and nitrate in the Atlantic Ocean, Bull. Bingham Oceanogr. Collect., I2(3), 169 pp., 1951.

Roemmich, D., and C. Wunsch, Apparent changes in the climatic state of the deep North Atlantic Ocean, Nature, 307, 447-450, 1984.

Roemmich, D., and C. Wunsch, Two transatlantic sections: Meridional circulation and heat flux in the subtropical North Atlantic Ocean, Deep Sea Res., 32, 619-665, 1985.

Sarmiento, J. L., C. G. H. Rooth, and W. Roether, The North Atlantic tritium distribution in 1972, J. Geophys. Res., 87, 8047-8056, 1982a.

Sarmiento, J. L., J. Willebrand, and S. Hellerman, Objective analysis of tritium observations in the Atlantic Ocean during 1971-74, Tech. Rep. 1, Ocean Tracers Lab., Dep. of Geol. and Geophys. Sci., Princeton Univ., Princeton, N. J., $1982 b$.

Schmitt, R. W., Growth rate of super-critical salt fingers, Deep Sea Res., 26A, 23-40, 1979.

Spencer, D. W., GEOSECS II, the North Atlantic Station hydrographic features of oxygen and nutrients, Earth Planet. Sci. Lett., I6, 91-102, 1972.

Takahashi, T., W. S. Broecker, and S. Langer, Redfield ratio based on chemical data from isopycnal surfaces, $J$. Geophys. Res., 90,6907 6924, 1985.

UNESCO, Tenth report of the joint panel on oceanographic tables and standards, Tech. Pap. Mar. Sci. 36, Paris, 1981.

Weisberg, R. H., and A. M. Horigan, Low-frequency variability in the equatorial Atlantic, J. Phys. Oceanogr., 11, 913-920, 1981.

Worthington, L. V., The $18^{\circ}$ water in the Sargasso Sea, Deep Sea Res., 5, 297-305, 1959.

Worthington, L. V., On the North Atlantic circulation, Johns Hopkins Oceanogr. Stud. 6, 110 pp., Johns Hopkins University Press, Baltimore, Md., 1976.

Wunsch, C., An estimate of the upwelling rate in the equatorial Atlantic based on the distribution of bomb radiocarbon and quasigeostrophic dynamics, J. Geophys. Res., 89, 7971-7979, 1984a.

Wunsch, C., An eclectic Atlantic Ocean circulation model, I, The meridional flux of heat, J. Phys. Oceanogr., 14, 1712-1733, 1984b.

Wust, G., Schichtungund Zirknlation des Atlantischen Ozeans: Die Stratosphäre (The Stratosphere of the Atlantic Ocean), in Wissenschaftliche Ergebnisse der Deutschen Atlantischen Expedition auf dem Forschungsund Vermessungsschiff "Meteor" 1925-1927, vol. 6 (1st part, 2), $180 \mathrm{pp} ., 1935$. (Translated for the office of the International Decade of the Ocean Exploration and the National Science Foundation, Washington, D. C., by the Al-Ahram Center for Scientific Translations, edited by W. J. Emery, 112 pp., Amerind, New Delhi, 1978.)

Wyrtki, K., The oxygen minima in relation to ocean circulation, Deep Sea Res., 9, 11-23, 1962

Young, W. R., and P. B. Rhines, A theory of the wind-driven circulation, II, Gyres with western boundary layers, J. Mar. Res., 40, $849-872,1982$.

M. Kawase and J. L. Sarmiento, Geophysical Fluid Dynamics Program, Princeton University, James Forrestal Campus, P.O. Box 308, Princeton, NJ 08542.

(Received November 21, 1984; accepted May 5, 1985.) 